\title{
Between- and within-country distributional impacts from \\ harmonizing carbon prices in the
}

EU

\section{Journal Article}

Author(s):

Landis, Florian; Fredriksson, Gustav; Rausch, Sebastian

Publication date:

2021-11

Permanent link:

https://doi.org/10.3929/ethz-b-000508379

Rights / license:

Creative Commons Attribution-NonCommercial-NoDerivatives 4.0 International

Originally published in:

Energy Economics 103, https://doi.org/10.1016/j.eneco.2021.105585 


\title{
Between- and within-country distributional impacts from harmonizing carbon prices in the $\mathrm{EU}^{\text {th }}$
}

\author{
Florian Landis ${ }^{\mathrm{a}, *}$, Gustav Fredriksson ${ }^{\mathrm{a}}$, Sebastian Rausch ${ }^{\mathrm{a}, \mathrm{b}}$ \\ ${ }^{a}$ Department of Management, Technology and Economics and Centre for Energy Policy and Economics (CEPE), ETH Zurich, Switzerland \\ ${ }^{\mathrm{b}}$ ZEW Leibniz Centre for European Economic Research, Mannheim, Germany, Department of Economics, and Heidelberg University, Germany
}

\section{A R T I C L E I N F O}

JEL classification:
C68
H23
Q43
Q52
Keywords:
Carbon pricing
Carbon market integration
EU climate policy
Distributional impacts
Cost effectiveness
Computable general equilibrium
Household heterogeneity

\begin{abstract}
A B S T R A C T
This paper examines the distributional impacts from (i) harmonizing prices for carbon dioxide emissions across sectors and EU countries and (ii) using alternative rules for carbon revenue distribution. We develop a numerical multi-country multi-sector general equilibrium model of the EU-27 economy which resolves household income deciles, based on micro-survey data on expenditure and income, and markets for fossil fuels, electricity, and (EU-wide and national) tradeable emissions rights. We find that carbon price harmonization yields efficiency gains at the EU level. The distributional effects between countries vary and depend largely on the redistribution of carbon revenues. Based on the rules currently in place in Phase IV of the EU ETS, efficiency gains flow disproportionately to low-income countries. Within-country incidence is progressive or neutral for most countries when revenue redistribution is ignored, and is not much affected by carbon price harmonization. Per-capita-based revenue redistribution rules lead to strong progressive outcomes and yield gains for low-income households. Evaluating different policy options using a social welfare function that incorporates inequality aversion suggests that there is no trade-off between efficiency and equity in harmonizing carbon prices in the EU economy.
\end{abstract}

\section{Introduction}

The European Green Deal foresees a tightening of climate targets for a sustainable EU economy. Raising the EU's greenhouse gas emissions reduction target for 2030 and achieving "climate neutrality" by 2050 requires a profound change in the way carbon dioxide $\left(\mathrm{CO}_{2}\right)$ emissions are priced in the EU economy. Under current EU climate policy, emissions are regulated under two separate schemes: the EU Emissions Trading System (EU ETS), which covers emissions from the electricity sector and energy-intensive industries, and the Effort Sharing Regulation (ESR), which defines national targets for transport, buildings, agriculture, and industries that fall outside the scope of the EU ETS. From a cost-effectiveness perspective, economists argue for expanding the sectoral and regional scope of carbon pricing to enhance whereflexibility (Böhringer et al., 2006; Goulder and Parry, 2008; Metcalf, 2009). As an important step towards carbon price harmonization, the European Commission (2021) has proposed to establish a second, standalone emissions trading system from 2026 onwards, which will cover emissions from buildings and road transport. Efficiency, however, is not the only yardstick: understanding the distributional effects both between and within countries is important to establish the political and social support for the future EU carbon pricing policy. The way in which the burdens and benefits of harmonizing carbon pricing in the EU are effectively distributed depends not only on direct policy choices about how to redistribute carbon pricing revenues to countries and households, but also on how a carbon price or multiple carbon prices in segmented markets influence the decisions of firms and households in decentralized and interconnected energy, emissions, product, and factor markets.

This paper examines the distributional effects between and within countries of harmonizing $\mathrm{CO}_{2}$ prices in the $\mathrm{EU}$, focusing on a set of stylized policy options that reflect likely policy paths for future EU carbon pricing policies. Specifically, we explore the distributional consequences of harmonizing $\mathrm{CO}_{2}$ prices across ETS and non-ETS sectors and across countries. We also examine how the choice of carbon

\footnotetext{
Disclaimer: This paper is based on data from Eurostat's 2010 Household Budget Survey (HBS) and Eurostat's 2010 European Union Statistics on Income and

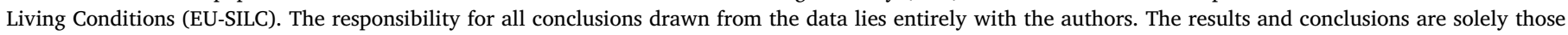
of the authors, and not those of Eurostat, the European Commission or any of the national statistical authorities whose data have been used.

* Correspondence to: Department of Management, Technology and Economics and Centre for Energy Policy and Economics (CEPE), ETH Zurich, Zürichbergstrasse 18, 8092 Zurich, Switzerland

E-mail addresses: landisf@ethz.ch (F. Landis), gfredriksson@ethz.ch (G. Fredriksson), sebastian.rausch@zew.de (S. Rausch).
} 
revenue redistribution affects the economic incidence from $\mathrm{CO}_{2}$ prices among heterogeneous households differentiated by income level and EU country of residence. We study different redistribution rules which define how carbon revenues available at the EU level are returned to countries and ultimately to households within a country. While we analyze redistribution across countries based on actual rules currently implemented in Phase IV of the EU ETS, we also investigate the economic consequences from drawing up redistribution rules based on population size and historical emissions. Given the ambitious emissions reduction targets in the $\mathrm{EU}$, we believe it is useful to understand how alternative criteria for redistribution affect distributional outcomes, given that the rules for burden (or effort) sharing will likely need to be renegotiated. For revenue redistribution within a country, we study per-capita (population-based) and emissions-based rules.

To quantitatively assess aggregate cost-effectiveness and distributional effects, we develop a numerical general equilibrium (GE) model focusing on the EU economy that resolves energy supply and demand for various energy sources (several fossil fuels and electricity), production and factor markets, national and EU-wide markets for tradable emission permits, intra-EU trade in goods and services, and existing product and income taxes. To our knowledge, we present the first GE model that distinguishes representative households for each EU country on the basis of income deciles, thus capturing household heterogeneity in terms of both spending behavior (consumption preferences) and income sources. We make use of comprehensive data for the European household population by combining expenditure data from Eurostat's Household Budget Survey (HBS) with income data from Eurostat's European Union Statistics on Income and Living Conditions (EU-SILC). The household microdata are integrated with data from the national income and product accounts of the Global Trade Analysis Project (GTAP).

Our main results are as follows. First, and in line with basic economic intuition, harmonizing $\mathrm{CO}_{2}$ prices between ETS and non-ETS sectors and between regions leads to efficiency gains at the EU level. Harmonization of non-ETS $\mathrm{CO}_{2}$ prices across regions alone already reduces losses in consumption utility from price-based climate policies in the EU, while the additional integration of non-ETS and ETS carbon markets leads to further improvement. At the same time, however, our results show that focusing on average (efficiency) effects at the EU level masks important heterogeneity across and within countries in terms of $\mathrm{CO}_{2}$ price effects. Second, we find that efficiency gains from full sectoral and regional harmonization of $\mathrm{CO}_{2}$ prices flow disproportionately to low-income EU countries when redistribution is based on the current EU ETS Phase IV rules. To the extent that equity concerns in European climate policy are about low-income countries bearing a disproportionate burden from carbon reductions, we find no pronounced efficiency-equity trade-off, i.e. expanding the scope of carbon pricing is possible without adverse effects for low-income countries. Third, we find that the impact of carbon pricing policies is progressively distributed across income deciles in most countries. ${ }^{1}$ Progressivity is more pronounced if per-capita based schemes for within-country revenue distribution are used. These schemes generate large utility gains for low-income households in all countries, and make them better off compared to richer households. Fourth, the within-country incidence is not much affected by alternative assumptions about $\mathrm{CO}_{2}$ price harmonization as it is mainly shaped by the choice of the within-country redistribution scheme. Fifth, the impact of carbon pricing without revenue redistribution is typically neutral to mildly progressive. Our analysis thus suggests that frequently voiced concerns over unintended regressive outcomes may be misplaced for most countries and potential regressivity can easily be avoided in all EU countries by appropriate revenue distribution. Sixth, decomposing the impacts of carbon

1 Policy impacts are said to be progressively distributed if the relative utility changes relative to no-policy are more beneficial for low-income households than they are for high-income ones. pricing into the uses of income and sources of income impacts, ${ }^{2}$ we find that the pattern of uses-side effects across income deciles differs between countries and do not always show a clear trend. The sourcesside effects show stronger trends and are markedly progressive for virtually all countries, and explain the overall progressive impacts from carbon pricing when ignoring revenue recycling. Seventh, using a social welfare function that incorporates inequality aversion, we find that harmonizing carbon prices beyond what is implied by current EU climate policy yields social welfare gains at the aggregate EU level independent of the redistribution scheme. Sufficiently harmonized $\mathrm{CO}_{2}$ prices combined with adequate redistribution rules even yield positive welfare changes compared to "no-climate policy" for an empirically plausible degree of social inequality aversion. Social welfare gains are particularly pronounced when taking into account both betweenand within-country distributional impacts-as opposed to only considering the distribution of mean impacts across countries-and a full redistribution of carbon revenues occurs. Notably, these gains do not include potential benefits from averted climate damages, suggesting an equity-driven strong double-dividend from carbon pricing in the EU.

This paper makes several contributions relative to the existing literature. First, our detailed micro-household data allow us to compare incidence outcomes within 21 European countries. Such multi-regional comparisons are scarce as most previous studies employing numerical general equilibrium models with multiple households focus on a single country (see van Ruijven et al., 2015, for a review of the literature) or sub-national regional detail (Rausch et al., 2011; Rausch and Karplus, 2014). Second, little research has examined the withincountry distributional effects of harmonizing carbon pricing across sectors in Europe. Some studies have investigated the impact of adding individual sectors, including agriculture (Ancev, 2011; De Cara and Vermont, 2011) and road transport (Achtnicht et al., 2019; Heinrichs et al., 2014; Flachsland et al., 2011), to an emissions trading system. These studies have typically ignored household incidence, however, and have instead focused on aggregate outcomes such as abatement costs and efficiency. The same can be said for the research on the effects of fully integrated carbon markets (see, for instance, Böhringer et al., 2005 for Europe and Labandeira et al., 2009 for Spain) which has also paid little attention to the distributional impacts within countries. We fill this research gap by analyzing how heterogeneous households are affected by increasingly harmonized carbon pricing in the EU. Finally, this paper provides novel insights into the economic implications of the current EU ETS redistribution rules. The role of revenue redistribution for improving equity is well-recognized in the literature (Williams III et al., 2015; Rausch and Schwarz, 2016), and the EU ETS auctioning rules are designed to especially compensate lower-income countries for their abatement cost. ${ }^{3}$ Previous research in the context of the third phase of the EU ETS suggests that this redistributive motive has been effective in shielding low-income member states from their abatement cost (Landis and Heindl, 2019). It is unclear, however, how the current Phase IV rules impact incidence within and across countries. This paper sheds light on this issue by comparing efficiency and distributional outcomes from the existing Phase IV rules with recycling schemes based on population size and historical emissions.

The remainder of this paper proceeds as follows. Section 2 presents our model. Section 3 describes the policy scenarios to examine the efficiency and distributional effects of $\mathrm{CO}_{2}$ price harmonization in the

\footnotetext{
2 The uses of income impact (uses-side effect) refers to how households' purchasing power changes as a result of the carbon price, while the sources of income (sources-side effect) refers to how households' nominal income is affected by changes in wages, capital rents, etc. In our analysis, the uses side accounts for all items that determine the consumption expenditure budget: not only income from labor, capital, and transfers, but also savings.

3 Directive EU 2018/410 (2021) explicitly assigns auctioning revenue shares to less wealthy member states that are higher than their shares in baseline emissions.
} 
EU economy. We present and discuss our main results in Section 4 (efficiency and distributional effects) and Section 5 (social welfare assessment). Section 6 concludes.

\section{Model}

\subsection{Overview}

We build on Abrell and Rausch (2016) and the GTAPinGAMS model type (Lanz and Rutherford, 2016) to develop a multi-region, multi-sector, multi-household numerical general equilibrium model. The model resolves EU member states as individual regions and incorporates detail on energy supply and use and carbon dioxide emissions related to the combustion of fossil fuels. We extend the model to incorporate household income deciles by country based on microhousehold survey expenditure and income data as well as climate policy mechanisms to represent the effects of carbon pricing on the EU economy. Table 1 provides an overview of the model resolution in terms of regions, sectors, households and factors of production.

The energy commodities represented in the model are coal, gas, crude oil, refined oil products and electricity. In addition, energyintensive sectors, which are potentially most affected by carbon pricing, are separately represented. All industries are characterized by constantreturns-to-scale production functions and firms within the industries are assumed to operate in perfectly competitive output and factor markets. Consumer preferences and production technologies are represented by nested constant-elasticity-of-substitution (CES) functions. ${ }^{4}$

In each region, consumption and savings result from the decisions of representative household groups, maximizing utility subject to a budget constraint requiring that expenditures plus savings equal income. Households in each region receive income from transfers and from inelastically supplying fixed endowments of the primary production factors: capital, labor, and specific resources for extraction or production of crude oil, natural gas, coal, and agriculture. Labor and capital inputs are treated as perfectly mobile between sectors within a region, but not mobile between regions. For capturing the distribution of policy costs across households of different income levels within EU member states, final household demand comprises ten representative household groups, corresponding to income deciles, in 20 member states and the UK. Thus, 21 countries are available for our within-country analysis. ${ }^{5}$

Bilateral international trade by commodity is represented following the Armington approach whereby like goods produced at different locations are treated as imperfect substitutes (Armington, 1969). A first nest aggregates imports of a certain good from different regions, and this aggregate enters a higher level nest where it is aggregated with the domestically produced variety (see Fig. A.4). Investment demand and the foreign account balance are assumed to be fixed.

A single government entity in each region represents government activities at all levels. The government collects revenues from income and commodity taxation and tariffs on international trade. Public revenues finance fixed amounts of government consumption and domestic (lump-sum) transfers to households (such transfers occur, for example, through social security systems). Aggregate government consumption is represented by a Leontief composite, i.e. inputs are combined in fixed proportions (see Fig. A.3).

\footnotetext{
4 Figs. A.1-A.3 and A.3 in Appendix A depict the nesting structures of the production functions and final demand.

5 Household data from the micro-surveys were not available for Austria and the Netherlands, and were incomplete for the Czech Republic, Italy, Luxembourg, Malta and Sweden. These seven member states were therefore excluded from the decile analysis. Household consumption in these countries, as well as in the other world regions outside the EU and the UK, is represented by a single aggregated household per region.
}

Table 1

Model resolution.

\begin{tabular}{|c|c|}
\hline Sectors & OIL ${ }^{\text {a }}$ Petroleum and coal products (refined), \\
\hline \multirow[t]{7}{*}{$g \in G$} & GAS $^{\mathrm{a}}$ Natural gas, ELE ${ }^{\mathrm{a}}$ Electricity, \\
\hline & COL $^{\text {a }}$ Coal, CRU ${ }^{a}$ Crude oil, \\
\hline & EIT $^{\mathrm{a}}$ Energy intensive goods, \\
\hline & TRN Transportation, AGR Agriculture, \\
\hline & MFR Other manufactured goods, \\
\hline & SER Services, C Household consumption, \\
\hline & G Government spending, I Investment \\
\hline Regions & CHN China, JPN Japan, KOR South Korea, IND India, \\
\hline \multirow[t]{13}{*}{$r \in R$} & CAN Canada, USA United States, BRA Brazil, RUS Russia, \\
\hline & ANZ Australia and New Zealand, MEA Middle East, \\
\hline & AFR Africa, OAM Other Americas, OAS Other Asia \\
\hline & AUT $^{\mathrm{b}}$ Austria, BEL ${ }^{\mathrm{b}, \mathrm{c}}$ Belgium, CYP ${ }^{\mathrm{b}, \mathrm{c}}$ Cyprus, \\
\hline & CZE $^{\mathrm{b}}$ Czech Republic, DNK ${ }^{\mathrm{b}, \mathrm{c}}$ Denmark, EST ${ }^{\mathrm{b}, \mathrm{c}}$ Estonia, \\
\hline & $\begin{array}{l}\text { GRC }^{\mathrm{b}, \mathrm{c}} \text { Greece, HUN }{ }^{\mathrm{b}, \mathrm{c}} \text { Hungary, IRL }{ }^{\mathrm{b}, \mathrm{c}} \text { Ireland, } \\
\text { Hend }\end{array}$ \\
\hline & ITA $^{\mathrm{b}}$ Italy, LVA ${ }^{\mathrm{b}, \mathrm{c}}$ Latvia, LTU ${ }^{\mathrm{b}, \mathrm{c}}$ Lithuania, \\
\hline & LUX $^{\mathrm{b}}$ Luxembourg, MLT ${ }^{\mathrm{b}}$ Malta, NLD ${ }^{\mathrm{b}}$ Netherlands, \\
\hline & POL $^{b, c}$ Poland, PRT ${ }^{b, c}$ Portugal, SVK ${ }^{b, c}$ Slovakia, \\
\hline & $\mathrm{SVN}^{\mathrm{b}, \mathrm{c}}$ Slovenia, ESP ${ }^{\mathrm{b}, \mathrm{c}}$ Spain, $\mathrm{SWE}^{\mathrm{b}}$ Sweden, \\
\hline & $\mathrm{GBR}^{\mathrm{b}, \mathrm{c}}$ United Kingdom, $\mathrm{CHE}^{\mathrm{b}}$ Switzerland, NOR ${ }^{\mathrm{b}}$ Norway, \\
\hline & $\mathrm{BGR}^{\mathrm{b}, \mathrm{c}}$ Bulgaria, HRV $\mathrm{H}^{\mathrm{b}, \mathrm{c}}$ Croatia, ROU ${ }^{\mathrm{b}, \mathrm{c}}$ Romania, \\
\hline & Len ou \\
\hline Factors & lab Labor, cap Capital, \\
\hline$f \in F$ & res Specific resources for sectors $\mathrm{G}$ \\
\hline Households & hh (if consumers are represented by one household) \\
\hline$h \in H_{r}$ & $\begin{array}{l}\mathrm{h} 1, \mathrm{~h} 2, \mathrm{~h} 3, \mathrm{~h} 4, \mathrm{~h} 5, \mathrm{~h} 6, \mathrm{~h} 7, \mathrm{~h} 8, \mathrm{~h} 9, \mathrm{~h} 10 \text { (if consumers are } \\
\text { represented by income deciles }\left[^{\mathrm{C}}\right] \text { ) }\end{array}$ \\
\hline
\end{tabular}

a Sectors covered by the EU ETS in all scenarios.

${ }^{\mathrm{b}}$ Regions covered by the EU ETS.

${ }^{\mathrm{c}}$ Regions with representation of household demand by deciles.

The model solves for equilibrium prices and quantities consistent with (1) profit- and utility-maximizing decisions by firms and households for production, consumption, and international trade and (2) market clearance on output and factor markets. Appendix A provides a complete algebraic representation of the model's equilibrium conditions.

\subsection{National accounts and micro-household survey data}

The social accounting matrices required for model calibration are based on data from version 9 of GTAP (Aguiar et al., 2016), which is benchmarked to 2011 and identifies 129 regions as well as 57 commodities. The GTAP9 dataset provides consistent global accounts of production, consumption, and bilateral trade as well as consistent accounts of physical energy flows and energy prices. We aggregate the GTAP dataset to 44 regions (30 European countries, and 14 aggregated regions representing the rest of Europe and the rest of the world) and 10 commodity groups (see Table 1). Primary factors in the dataset include labor, capital, and natural resources.

We make use of comprehensive micro-household survey data from Eurostat to represent deciles of household consumption. On the expenditure side, the 2010 wave of the Household Budget Survey (HBS) provides detailed information on household consumption in the form of the Classification of Individual Consumption by Purpose (COICOP). Households are aggregated into deciles according to their income, weighted by their statistical weights (variable EUR_HH095). On the income side, the 2010 wave of the European Union Statistics on Income and Living Conditions (EU-SILC) contains information on the composition of household income. Here, too, households are weighted according to their statistical weights and aggregated into income deciles (using disposable income; variable HY020).

The COICOP subcategories in the HBS are matched to the ten goods in our model (see Table 1), while the EU-SILC items are aggregated to 
the GTAP income categories labor, capital and transfers. ${ }^{6}$ We associate the residual between each household decile's income and consumption expenditure with household savings which are represented by expenditures on the model's investment good. Summing up income and expenditure per category in the surveys across deciles yields national values for commodity-specific consumption expenditures, labor income, transfer income, and savings.

To create the model's deciles, we allocate national GTAP expenditures on primary energy goods (OIL, GAS, and COL) to the model's deciles according to the HBS deciles' shares in national spending on the respective energy good. ${ }^{7}$ We allocate spending on the remaining consumption categories ("other goods") to the model's deciles such that the model's deciles' share in expenditure on other goods is the same as the HBS deciles' share in national expenditure on other goods (same shares for all categories of other goods). For income, we allocate national GTAP income from labor, capital, and resources to the model's deciles according to the EU-SILC deciles' share of income from labor and capital (we use the latter for both GTAP capital and resource income) in national income from those sources. We take transfer income directly from the EU-SILC deciles. Savings at the national and decile level result as the residual between income and consumption expenditure. (The data harmonization procedure presented here is detailed in Appendix B.) Since the sum of investments by the model's deciles implied by these residuals does not agree with the investment spending of GTAP, the national governments compensate for this. ${ }^{8}$

\section{Policy scenarios}

Table 2 provides an overview of the different policy scenarios for $\mathrm{CO}_{2}$ price harmonization in Europe. We examine three stages of $\mathrm{CO}_{2}$ market integration, ranging from the current policy situation of segmented carbon markets as represented by the EU ETS and countryspecific targets for non-ETS sectors, to an intermediate case of two emissions trading systems, to a (hypothetical) fully integrated EU carbon market:

EU ETS + national pricing: The emissions of energy-intensive sectors are covered by the EU ETS, an EU-wide emissions trading system, where all emission permits are auctioned. Table 1 details the sectoral and regional scope of the EU ETS in terms of our model. Non-ETS emissions targets are met by each country through an endogenous national $\mathrm{CO}_{2}$ price that equalizes marginal abatement costs across that country's non-ETS sectors. ${ }^{9}$

\footnotetext{
6 The mappings used for consumption and income are available on request from the authors.

7 The HBS reports household-level expenditure on solid fuels (variable EUR_HE04541), which includes coal (COL) but also solid biofuels (wood; supplied by MFR). We distribute national household coal consumption in GTAP across deciles according to solid fuels consumption in the HBS and assign the remaining solid fuels expenditure to the GTAP sector MFR.

8 Since differences between the data sets in the aggregates per category are large (see Table C.1 in Appendix C), it is a priori unclear to what extent different ways of reconciling the data create different results. An alternative way of data reconciliation is to take survey quantities at face value for creating the deciles and then allocating the income and expenditures remaining in national accounts to a "residual household". For a meaningful welfare analysis, real consumption of the residual household should be kept constant which can be achieved by lump-sum transfers from representative income deciles. We find that under this alternative calibration, since for many countries the deciles' expenditure is much smaller than national sums, carbon pricing revenue recycling volumes are much bigger relative to decile expenditure. This leads to much more pronounced effects of revenue recycling on relative changes in consumption utility.

9 A country's non-ETS sectors will therefore abate different amounts, as sectors with lower marginal abatement costs will reduce comparatively more emissions. The sum of abatement across a country's non-ETS sectors, however, will correspond to the total abatement mandated by the national non-ETS target.
}

We argue that this scenario is the closest to current policy practice where member states largely adhere to their non-ETS targets implied by the EU Effort Sharing Regulation and do not make use of their possibilities for trading abatement obligations between them. ${ }^{10}$

EU ETS + trade among non-ETS sectors: The emissions of energyintensive sectors are covered by an EU-wide emissions trading system where all emission permits are auctioned, and abatement obligations for non-ETS emissions are traded such that $\mathrm{CO}_{2}$ prices required for reaching them are equalized across all countries participating in the EU ETS. This leads to the same total non-ETS emission levels across the participants in the EU ETS as in EU ETS + national pricing. This scenario reflects a likely path for future EU climate policy in line with the recent proposal by the European Commission (2021). ${ }^{11}$

Full ETS: All carbon emissions of the countries participating in the EU ETS are covered by a single European ETS.

The second dimension of our scenarios pertains to the policy choice of how carbon pricing revenue is recycled between countries participating in the EU ETS and between heterogeneous households within a given participating country. Throughout, we assume that emission permits are fully auctioned. ${ }^{12}$ Our assumptions regarding the inter- and intra-regional distribution of the carbon revenue are as follows:

Phase IV rules: the revenue is distributed across regions according to the current rules for allocating auctioned allowances in Phase IV of the EU ETS, as outlined in Directive EU 2018/410 (2021). ${ }^{13}$ These rules are to a large extent based on countries' benchmark ETS sector emissions in 2005, but generously allocate allowances to lower-income member states (by allocating them more auctioning revenue than their shares in benchmark emissions would justify). Within regions, revenue is either recycled

10 Under current regulation, there are a variety of different national policies in non-ETS sectors. We do not model these policies in detail, but represent them through a national emissions trading scheme. Therefore, to the extent that national regulatory policies are less efficient than a carbon price, our analysis may underestimate the efficiency gains from moving to an emissions trading system for non-ETS sectors.

11 Even without the introduction of a separate ETS for emissions covered by the effort sharing agreement, current flexibility measures in EU regulation mean that member states can, in principle, trade abatement obligations. Therefore, if member states start to make use of this possibility, the EU climate policy framework may become more similar to this EU ETS + trade among non-ETS sectors scenario.

12 Our perspective is on the design of a future European ETS which has moved beyond a partial grandfathering of allowances.

13 These rules can be summarized as follows: (1) two percent of total allowances will be distributed as auctioning permits to member states covered by the Modernization Fund. We assume that this amount corresponds to 3.51 percent of all auctioned allowances, since 57 percent of total allowances will be auctioned in Phase IV; (2) Of the remaining allowances to be auctioned: (a) 90 percent will be distributed in shares proportional to member states' greenhouse gas emissions from EU ETS installations in 2005 or the average in 2005-2007 (whichever is highest); and (b) 10 percent will be allocated to less wealthy member states by adjusting the shares in (a) in line with Annex IIa of Directive 2009/29/EC (2021) and the Treaty of Accession of Croatia (2012). We distribute the permits in the Phase IV rules scenarios according to these rules, with some slight modifications. For internal consistency in the model, we calculate the shares in (2a) using the energy-related $\mathrm{CO}_{2}$ emissions from the model's EU ETS sectors (see Table 1) in the GTAP9 2004 base year. Furthermore, we apply the above rules to economy-wide energy-related $\mathrm{CO}_{2}$ emissions in the GTAP9 2004 base year in the Full ETS scenarios to reflect the expanded scope of the ETS. This explains the different auctioning revenue shares between the Phase IV rules scenarios in Table 3. 
Table 2

Scenario overview.

\begin{tabular}{|c|c|c|c|c|}
\hline \multirow[t]{3}{*}{$\begin{array}{l}\text { Carbon market } \\
\text { integration }\end{array}$} & & \multirow{2}{*}{\multicolumn{3}{|c|}{$\begin{array}{l}\text { Between- and within-country distribution } \\
\text { of carbon revenues } \\
\qquad \text { across households within countries }\end{array}$}} \\
\hline & & & & \\
\hline & & & $\begin{array}{l}\text { Household } \\
\text { size }\end{array}$ & $\begin{array}{l}\text { Direct emissions } \\
\text { in consumption }\end{array}$ \\
\hline $\begin{array}{l}\text { EU ETS + } \\
\text { national } \\
\text { pricing }\end{array}$ & & $\begin{array}{l}\text { EU ETS } \\
\text { Phase IV } \\
\text { rules }\end{array}$ & $\begin{array}{l}\text { Phase IV rules } \\
+ \text { per-capita }\end{array}$ & $\begin{array}{l}\text { Phase IV rules } \\
+ \text { emissions }\end{array}$ \\
\hline $\begin{array}{l}\text { EU ETS + } \\
\text { trade among } \\
\text { non-ETS sectors }\end{array}$ & \multirow[t]{2}{*}{$\begin{array}{l}\text { between } \\
\text { countries }\end{array}$} & $\begin{array}{l}\text { Population } \\
\text { size }\end{array}$ & Per-capita & - \\
\hline Full ETS & & $\begin{array}{l}\text { Historical } \\
\mathrm{CO}_{2} \\
\text { emissions }\end{array}$ & - & Emissions \\
\hline
\end{tabular}

on a per-capita lump-sum basis (Phase IV rules + per-capita) or in proportion to households' direct (i.e., not embodied) $\mathrm{CO}_{2}$ emissions from private consumption in 2010 (Phase IV rules + emissions).

Per-capita: the revenue is distributed across participating countries in proportion to population size, and each member state recycles the revenue to households on a per-capita lump-sum basis.

Emissions: the revenue is distributed across participating countries in proportion to countries' emissions in 2011, and each country distributes the revenue to households in proportion to households' direct $\mathrm{CO}_{2}$ emissions from private consumption in $2010 .{ }^{14}$

Table 3 provides the resulting shares according to which ETS revenue is allocated among EU member states under the alternative distribution schemes.

With regard to the targeted $\mathrm{CO}_{2}$ emission reductions, we assume a world in which the non-EU regions (excluding the UK) achieve their Nationally Determined Contributions (NDCs) from the Paris Agreement. Regions that do not participate in the EU ETS regulate their emissions through regionally uniform $\mathrm{CO}_{2}$ prices. Total EU ETS emissions are reduced by 43 percent relative to 2005 . In line with the common assumptions from the EMF36 study, we incorporate projections about no-policy emissions growth until 2030 and derive country-specific emissions reduction with respect to this baseline. The non-ETS reduction targets of EU member states and the UK are those stipulated by the Effort Sharing Regulation. ${ }^{15}$

Throughout our analysis, we invoke an equal-yield constraint whereby governments adjust their taxation of final consumption in order to achieve constant real public expenditure relative to the benchmark without climate policy. The purpose of this is to keep all components of final demand except household consumption constant so that the latter is a meaningful welfare measure. This is necessary since our model does not account for the utility generated by investments or government spending. Balancing the budget of the government, by adjusting taxation of final consumption, ensures that the full value of the carbon pricing revenue is available for redistribution, even though climate policy erodes the tax base for non-carbon related taxes.

\footnotetext{
14 Countries' emissions are given by GTAP for the year 2011, while the expenditure on fossil fuels across households is given by the HBS for 2010 .

15 Table C.2 in Appendix C shows the reduction targets for non-ETS emissions for participants in the EU ETS compared to the 2030 no-policy baseline. Country-specific reductions targets range from a slight overallocation of emissions for Romania to a reduction of 58 percent for the case of Norway.
}

Table 3

Index of per-capita income at purchasing parity and carbon revenue share by country under alternative distribution schemes.

\begin{tabular}{|c|c|c|c|c|c|}
\hline \multirow[t]{3}{*}{ Country } & \multirow[t]{3}{*}{ PPP index ${ }^{\mathrm{a}}$} & \multicolumn{4}{|c|}{ Carbon revenue share (percent) } \\
\hline & & \multicolumn{2}{|c|}{ EU ETS Phase IV rules } & \multirow[b]{2}{*}{$\begin{array}{l}\text { Population } \\
\text { size }\end{array}$} & \multirow[b]{2}{*}{$\begin{array}{l}\text { Historical } \\
\text { emissions }\end{array}$} \\
\hline & & $\begin{array}{l}\text { Segmented carbon } \\
\text { markets }{ }^{\mathrm{b}}\end{array}$ & Full ETS & & \\
\hline EST & 0.63 & 0.24 & 0.31 & 0.25 & 0.21 \\
\hline ROU & 0.68 & 4.53 & 3.21 & 3.37 & 2.06 \\
\hline BGR & 0.69 & 2.44 & 1.58 & 1.20 & 1.26 \\
\hline HUN & 0.71 & 1.67 & 1.67 & 1.78 & 1.16 \\
\hline HRV & 0.71 & 0.65 & 0.66 & 0.72 & 0.51 \\
\hline CZE & 0.75 & 5.16 & 3.64 & 2.00 & 2.65 \\
\hline POL & 0.82 & 13.67 & 9.77 & 6.98 & 7.66 \\
\hline SVK & 0.83 & 1.39 & 1.14 & 1.01 & 0.72 \\
\hline SVN & 0.89 & 0.40 & 0.39 & 0.39 & 0.42 \\
\hline MLT & 0.90 & 0.11 & 0.10 & 0.11 & 0.10 \\
\hline LVA & 0.93 & 0.25 & 0.35 & 0.33 & 0.26 \\
\hline PRT & 0.93 & 1.49 & 1.51 & 1.87 & 1.41 \\
\hline SWE & 1.00 & 0.71 & 1.14 & 2.15 & 1.24 \\
\hline DNK & 1.01 & 1.30 & 1.44 & 1.15 & 1.68 \\
\hline ESP & 1.01 & 7.95 & 7.90 & 8.97 & 7.43 \\
\hline GRC & 1.03 & 2.85 & 4.84 & 1.94 & 5.36 \\
\hline NLD & 1.06 & 3.71 & 3.86 & 3.32 & 4.49 \\
\hline CYP & 1.08 & 0.21 & 0.32 & 0.18 & 0.35 \\
\hline IRL & 1.09 & 0.85 & 1.03 & 0.99 & 1.17 \\
\hline NOR & 1.11 & 1.00 & 1.36 & 1.07 & 1.74 \\
\hline FIN & 1.12 & 1.82 & 1.39 & 1.04 & 1.46 \\
\hline ITA & 1.13 & 9.52 & 9.88 & 11.00 & 10.28 \\
\hline LUX & 1.15 & 0.10 & 0.33 & 0.14 & 0.41 \\
\hline FRA & 1.16 & 4.34 & 8.53 & 12.90 & 9.44 \\
\hline LTU & 1.17 & 0.48 & 0.45 & 0.46 & 0.30 \\
\hline GBR & 1.18 & 11.82 & 11.94 & 13.34 & 12.43 \\
\hline BEL & 1.18 & 1.70 & 2.30 & 2.22 & 2.73 \\
\hline AUT & 1.25 & 1.04 & 1.49 & 1.75 & 1.61 \\
\hline DEU & 1.34 & 18.35 & 16.49 & 15.65 & 18.34 \\
\hline CHE & 1.47 & 0.22 & 0.97 & 1.72 & 1.10 \\
\hline
\end{tabular}

a The index of per-capita expenditure budget at purchasing parity (PPP index) is normalized to the mean of the EU28 + Norway \& Switzerland ( $1=2011$ US\$ 21'001). ${ }^{\mathrm{b}}$ Segmented carbon markets refer to the scenarios EU ETS + national pricing and EU ETS + trade among non-ETS sectors.

\section{Harmonizing $\mathrm{CO}_{2}$ prices in the EU: Efficiency and distributional effects}

In presenting our main results, we focus first on the efficiency effects of the alternative carbon market and revenue-recycling options at the EU-aggregate and country level, followed by an analysis of the withincountry distribution of effects at the household level. Finally, we offer an integrated view in Section 5 that considers aspects of efficiency and equity together by applying an Atkinsonian social welfare function 
approach that incorporates social preferences with respect to inequality between and within countries.

\subsection{Measuring utility changes}

We use equivalent variation (EV), relative to the annual expenditure budget in the no-policy baseline, to assess the utility impacts at the household decile level within countries and at the country level. EV corresponds to percent changes in money-metric utility, i.e. by what percentage would the baseline expenditure budget have to be changed to achieve the counterfactual consumption utility at baseline prices. In averaging effects across countries, we report two measures: (i) percapita averages of EV ("EV" in short) and (ii) purchasing power parity (PPP)-adjusted per-capita averages of EV ("PPP-adjusted EV"). Ranking scenarios by PPP-adjusted EV does not allow for the same conclusions about Pareto improvements between scenarios as does ranking scenarios by EV. ${ }^{16}$

Metric (i) is a standard measure of overall economic efficiency. To assess the desirability of various policies, policymakers may, however, also be interested in the average consumption opportunities that the policies bring. Since the same amount of money has different purchasing power in different countries, household expenditure budgets in different countries should be adjusted for this to determine how wealthy citizens are on average. ${ }^{17}$ These considerations motivate our metric (ii).

\subsection{Efficiency gains at the EU level}

Fig. 1 shows on the left axis the PPP-adjusted EV and EV for countries in the EU ETS in $\$ 2011$ per-capita; on the right axis, it shows the dispersion of country-level PPP-adjusted EV, as measured by the coefficient of variation (CV). The following insights emerge.

First, comparing the scenarios in terms of $\mathrm{EV}$, we find that $\mathrm{CO}_{2}$ price harmonization yields efficiency gains, while the patterns of redistribution of EU ETS auction revenues have a limited impact on efficiency. A greater degree of $\mathrm{CO}_{2}$ price harmonization also tends to reduce the PPPadjusted EV loss and the choice of the redistribution schemes affects the mean impacts as well. Improving over the current $\mathrm{CO}_{2}$ market segmentation as implied by EU ETS + national pricing yields large utility gains. Linking non-ETS sectors across regions already reaps most of the gains. Adding the sectoral link between ETS and non-ETS (i.e., going from EU ETS + trade among non-ETS sectors to Full ETS) reduces the utility cost further and the reduction is biggest under the redistribution scheme Phase IV rules.

Second, the ranking of the redistribution rules in terms of PPPadjusted EV is the same for all levels of market integration. Redistribution based on Phase IV rules causes the smallest utility loss, which is due to the fact that Phase IV rules systematically allocates large shares of ETS allowance revenues (large relative to shares of ETS base-year emissions) to low-income member states, where the money tends to have higher purchasing power.

Third, the CV measures the dispersion of mean impacts across countries that result from different carbon policy options. It is thus an indicator of policy-induced inequality of the distributional effects. The

16 Our model with exogenous PPP (i.e. PPP does not change across policy scenarios) is unfit for finding optimal policies in terms of PPP-adjusted EV. The model would suggest giving all the money generated in Europe to consumers in the country where the money has the highest purchasing power (leaving nothing to consumers in other countries). We do not attempt to find an optimal policy and confine our analysis to comparing different plausible policy proposals, and describing the scenario outcomes in terms of PPP-adjusted EV is meaningful.

17 For calibrating purchasing power, we rely on the results of the International Comparison Program (ICP), available at https://www.worldbank.org/ en/programs/icp (see World Bank, 2020). addition of regional and sectoral abatement flexibility not only leads to utility gains at the EU level, but also generates higher variation in impacts. For a given level of $\mathrm{CO}_{2}$ price harmonization, using Phase IV rules for redistribution leads to higher values of $\mathrm{CV}$. It is unclear a priori how this increase in heterogeneity affects the distribution of country-level impacts. In particular, the question arises whether harmonization of $\mathrm{CO}_{2}$ prices involves relevant trade-offs between efficiency and equity.

\subsection{Distribution of country-level impacts in the EU}

Fig. 2 shows the distribution of country-level EV for two selected $\mathrm{CO}_{2}$ price harmonization scenarios. Comparing Panels (a) and (b) in Fig. 2 suggests that the lowest-income countries prefer the outcome under Full ETS to the outcome under EU ETS + national pricing for most redistribution rules. Under both EU ETS + national pricing and Full ETS, redistribution of carbon revenues under Phase IV rules tends to make overall climate policy outcomes attractive to low-income countries. Comparing Panels (a) and (b) suggests that the efficiency gains from a full sectoral and regional harmonization of carbon prices do not stand in contrast to the equity aspect that poor countries should not carry a disproportionate part of the policy cost. In fact, the lowest income countries are overcompensated, and carbon price harmonization and redistribution according to Phase IV rules only means that the efficiency gains flow disproportionally to poorer countries. This effect becomes stronger as more carbon revenues are distributed under the Phase IV rules in the scenario Full ETS when emissions of all sectors are regulated under a single ETS.

The differences in country-level impacts are mainly due to differences in the distribution of carbon revenues under the various redistribution rules. Fig. 3 shows the impact of different policy choices on $\mathrm{CO}_{2}$ prices and carbon revenues. Panel (a) shows $\mathrm{CO}_{2}$ prices for $E U$ ETS + national pricing and Full ETS: national non-ETS carbon prices (round markers) and the ETS-wide permit price (solid line) for $E U$ ETS + national pricing and the economy wide ETS permit price for Full ETS (dashed line). The large differences in national non-ETS $\mathrm{CO}_{2}$ prices indicate the large potential for efficiency gains from $\mathrm{CO}_{2}$ price harmonization. At the same time, the price of ETS permits under EU ETS + national pricing is lower than national $\mathrm{CO}_{2}$ prices for virtually all big EU economies, which explains further efficiency gains from integrating all sectors into the ETS. The non-ETS $\mathrm{CO}_{2}$ prices and ETS permit prices are very similar across the redistribution schemes and we only show prices for the redistribution scheme Emissions. Panel (b) of Fig. 3 shows the allocation of revenues from carbon pricing to different countries under Full ETS. Since $\mathrm{CO}_{2}$ prices change little with different distribution patterns, changes in revenues are driven almost entirely by patterns of redistribution of ETS permit auction revenues. At the same time, in a given country, similar $\mathrm{CO}_{2}$ prices imply similar abatement levels and thus similar abatement costs. Therefore, differences in carbon revenues across countries are a key driver of differences in country-level benefits under scenarios with different redistribution rules. Comparing the Panels (b) in Figs. 2 and 3 shows that in each country the ranking of redistribution schemes in terms of EV (Fig. 2) is well predicted by the redistribution of revenues from carbon pricing (Fig. 3).

\subsection{Distribution of household-level impacts within EU countries}

Fig. 4 shows the utility impacts by country and household income decile (measured as EV relative to "no-climate policy" consumption expenditures) of a European carbon pricing regime as in EU ETS + national pricing and alternative redistribution rules. ${ }^{18}$ Several insights emerge.

\footnotetext{
18 Progressive outcomes show a negative slope of policy impacts across income deciles, regressive outcomes a positive slope, and neutral outcomes correspond to (more or less) equal relative EV outcomes for all deciles.
} 


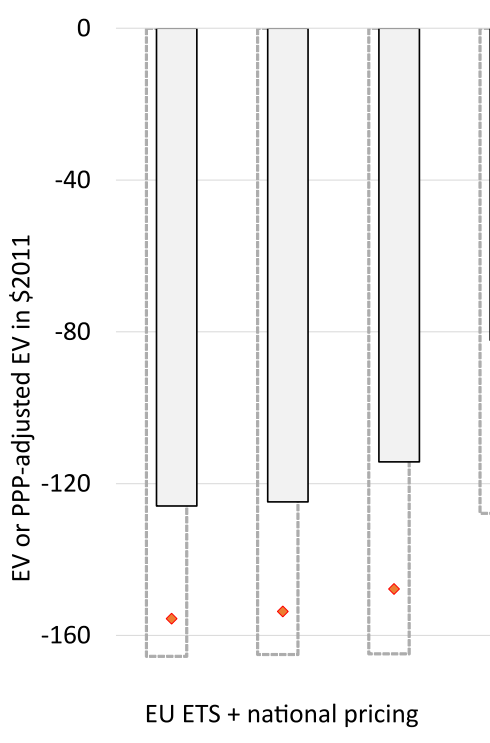

$-200$

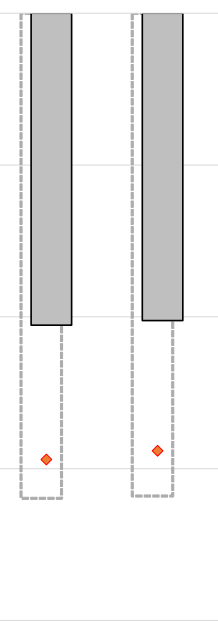

EU ETS + trade among non-ETS sectors

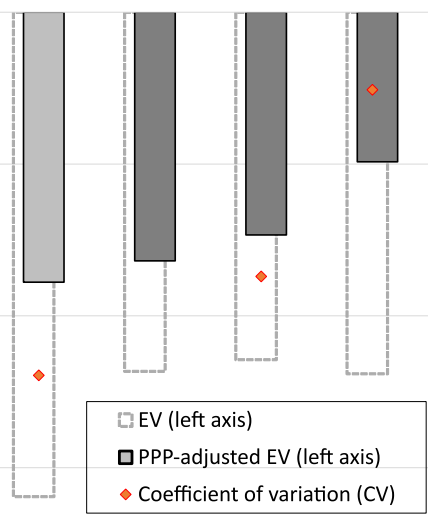

$\diamond$
8

7

6

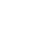

5

u

4

4

3

2

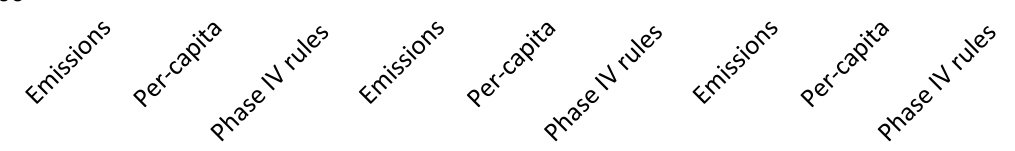

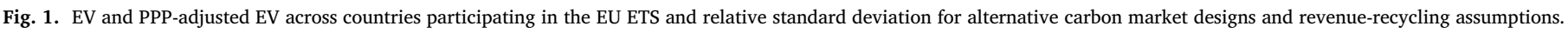
Note: For the Phase IV rules scenario, revenues within countries are recycled in proportion to household emissions.

First, independent of the redistribution rule, the impacts are progressive for almost all countries, i.e. disproportionately benefiting lowincome households. Exceptions are Estonia (EST), Romania (ROU), and Bulgaria (BGR). Schemes that redistribute carbon revenues within a country on a per-capita basis (EU ETS + national pricing \& Per-capita and EU ETS + national pricing \& Phase IV rules + per-capita) lead to progressive outcomes for all countries and these outcomes are more progressive as compared to redistributing revenue based on benchmark emissions (EU ETS + national pricing \& Emissions). Recycling carbon revenues on a per-capita basis skews outcomes towards progressivity, since per-capita payments are larger compared to baseline expenditures for low-income households. ${ }^{19}$ Second, for low-income countries-following the ordering of countries according to per-capita consumption budget in PPP from left to right-the redistribution of carbon revenue based on emissions considerably dampens progressivity to the point where policy impacts are nearly distributionally neutral or even regressive. Third, per-capita based redistribution of carbon revenues within a country leads to substantial utility gains from climate policies for low-income households in both rich and poor EU countries. Under the per-capita based redistribution rules, low-income households are better off than high-income households in all countries. Taken together, these observations make it clear that, for a given carbon pricing regime, economic incidence crucially depends on the choice of the redistribution rule and that per-capita redistribution within countries can easily address adverse impacts on low-income households.

Does $\mathrm{CO}_{2}$ price harmonization affect the within-country incidence (for a given redistribution rule)? Fig. 5, Panel (a), bears out the main insight that the sectoral and regional scope of the carbon pricing does not have much of an impact on the household-level distribution of utility impacts within a country. Intuitively, the reason is that

19 The case of Estonia (EST) is notable. Its relatively high non-ETS carbon price in EU ETS + national pricing scenarios creates high volumes of revenue for recycling. When recycled on a per-capita basis, this leads to extremely progressive outcomes. household incidence is mainly shaped by the choice of the (withincountry) redistribution rule. However, there are differences for some groups of countries. First, low-income countries (for example, Romania (ROU), Bulgaria (BGR), Hungary (HUN), Croatia (HRV), Poland (POL), and Slovakia (SVK)) experience more progressive outcomes as $\mathrm{CO}_{2}$ price harmonization increases. The results in Fig. 3 show that these countries' revenues generally increase when moving from EU ETS + national pricing to Full EU ETS, for example. The increase in carbon revenues explains why the distributional impacts of the redistribution rules becomes more pronounced in Panel (a) of Fig. 5.

To better understand how the within-country household impacts of carbon pricing are determined by the redistribution rule, Panel (b) in Fig. 5 reports household-level utility impacts by country without and with carbon revenue redistribution (showing the case of Full ETS \& Phase IV rules + per-capita). ${ }^{20}$ Two important insights emerge. First, the impact of carbon pricing without revenue redistribution is mostly progressive already. Importantly, the analysis based on this model and the underlying data therefore suggests that the full lump-sum recycling of carbon revenue is not needed to address equity concerns over regressive outcomes of carbon pricing. Second, the full redistribution of carbon revenues on a per-capita basis is markedly progressive for all countries. The fact that we observe a clearly progressive incidence in all countries is to a large part driven by the distributional effect of carbon revenue redistribution.

\subsection{Drivers of distributional impacts by household decile when carbon revenues are ignored}

Fig. 6 sheds further light on the result that the distributional impacts of carbon pricing by household decile without revenue recycling are

\footnotetext{
20 To trace out the impact on consumer utility without revenue recycling, we correct the equivalent variation by the relative change in expenditure budgets if transfers due to revenue recycling were not received. In general equilibrium, this corresponds to a situation where the government uses the carbon pricing revenue to buy the same goods as the households would have (without any use to anybody).
} 


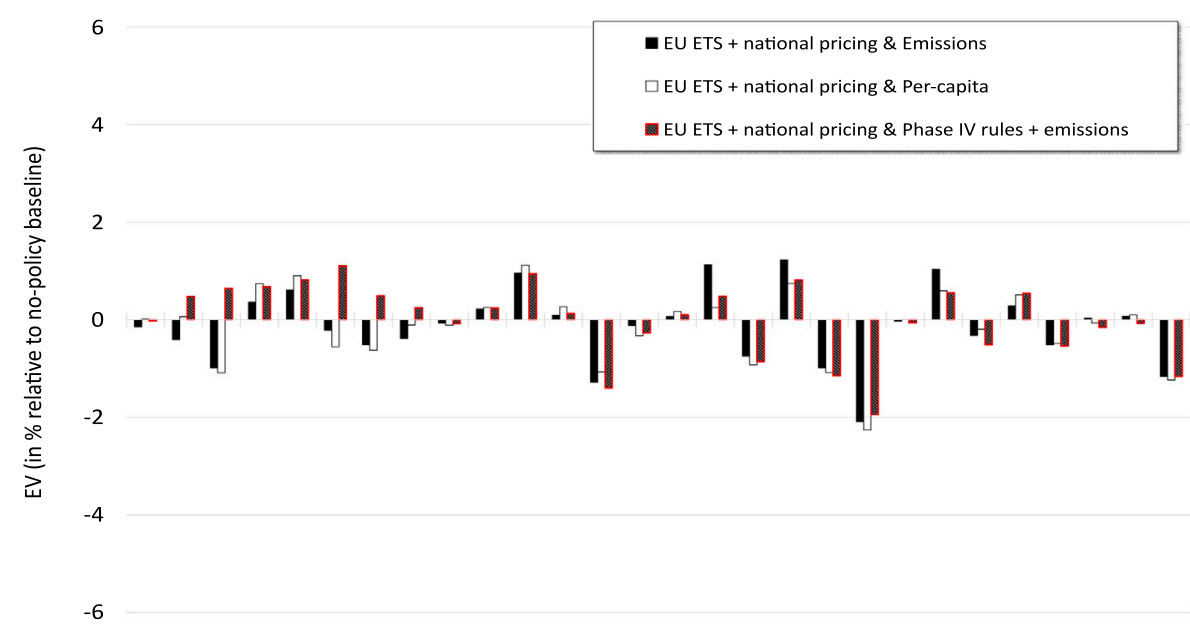

$-8$

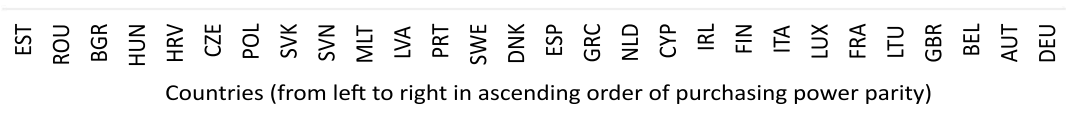

Panel (a): EU ETS + national pricing

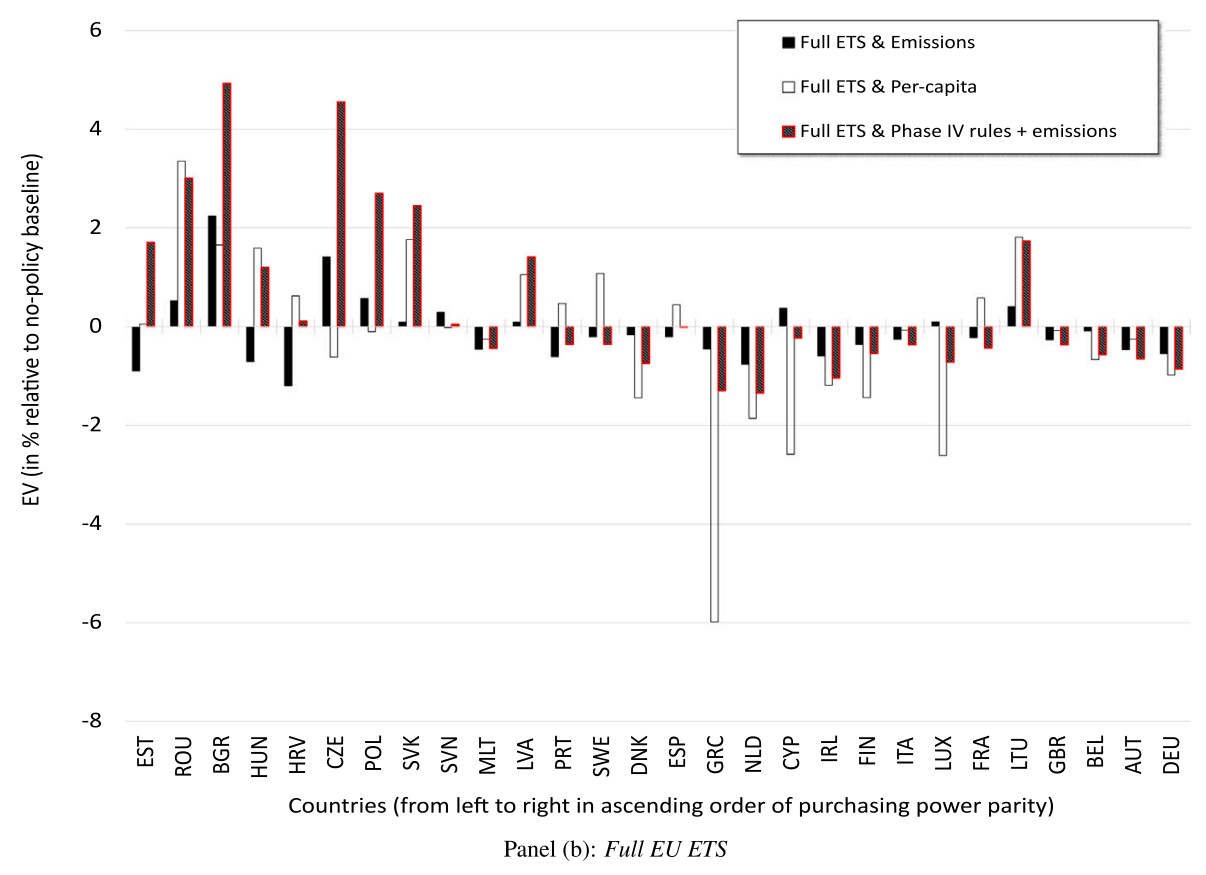

Fig. 2. EV by country for various levels of carbon market integration (panels) and redistribution schemes (data series within panels).

mostly progressive (as shown by Panel (b) in Fig. 5). ${ }^{21}$ To this end, we decompose household utility impacts before revenue recycling in uses-side and sources-side effects. ${ }^{22}$ Panel (a) of Fig. 6 shows that

21 This result was shown first for the U.S. context by Rausch et al. (2011) and confirmed by Goulder et al. (2019). The present paper provides the first assessment for the European context, looking at the within country household incidence of carbon pricing in a modeling framework that resolves European countries.

22 We decompose the impact on consumption utility $u$ of a carbon policy as follows (where $m$ and $p$ denote expenditure budget and the consumer price index, respectively): $\frac{d u}{u}=\frac{d(m / p)}{m / p}=\frac{\frac{m+d m}{p+d p}-\frac{m}{p}}{m / p}=\frac{d m}{m}-\frac{m+d m}{m} \frac{d p}{p+d p} \approx \frac{d m}{m}-\frac{d p}{p}$, where $-d p / p$ measures the uses-side effect and $d m / m$ the sources-side effect. Note that the last approximation requires sufficiently small carbon price interventions which is reasonable given the nature of policy scenarios considered here. the uses-side effects tend to be progressive for the lowest-income EU member states and neutral to slightly regressive in higher-income EU member states.

The uses-side effects are largely driven by the additional expenditures each household incurs due to a $\mathrm{CO}_{2}$ price. Fig. C.1 in Appendix C shows that the uses-side effects strongly correlate with the households' emissions intensity of consumption expenditures in the "no-climate policy" benchmark. We find that on the sources side, distributional effects are markedly progressive for virtually all EU countries, following the intuition that high-income households suffer from disproportionately large losses in capital and labor income while low-income households receive a high share of income from pre-existing transfers which are indexed to inflation (i.e., which we assume to remain constant in our policy scenarios). Fig. C.2 in Appendix C shows the composition of household income across deciles in the "no-climate policy" benchmark. 

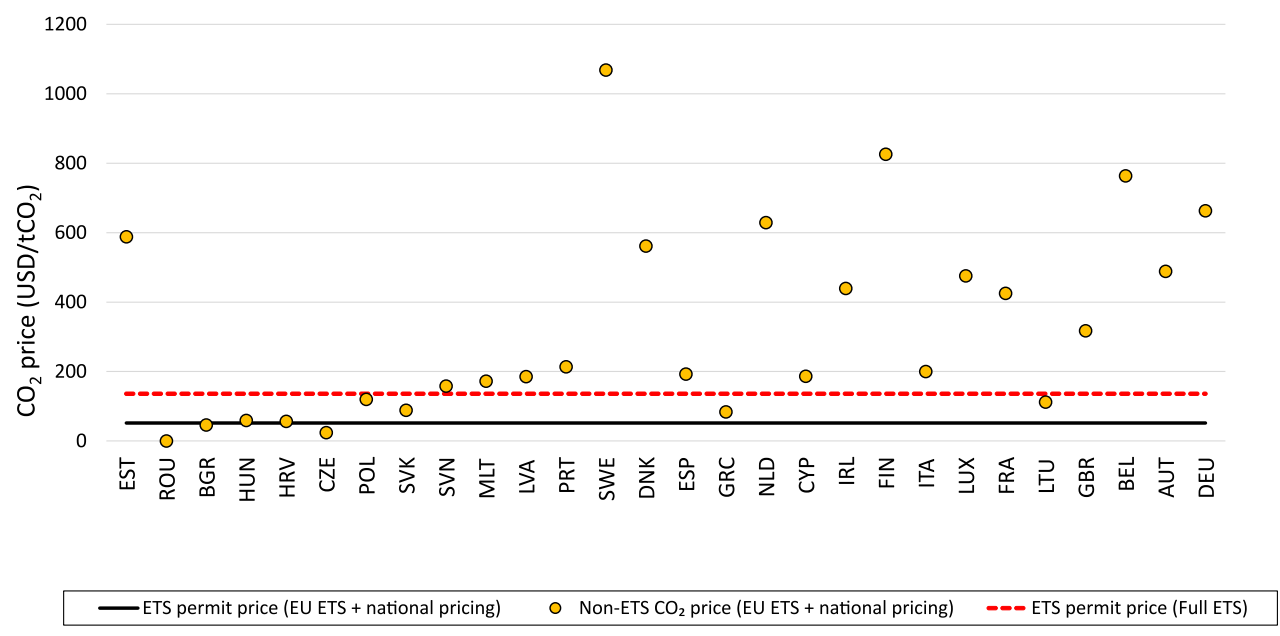

Panel (a): $\mathrm{CO}_{2}$ prices for EU ETS + national pricing and Full ETS

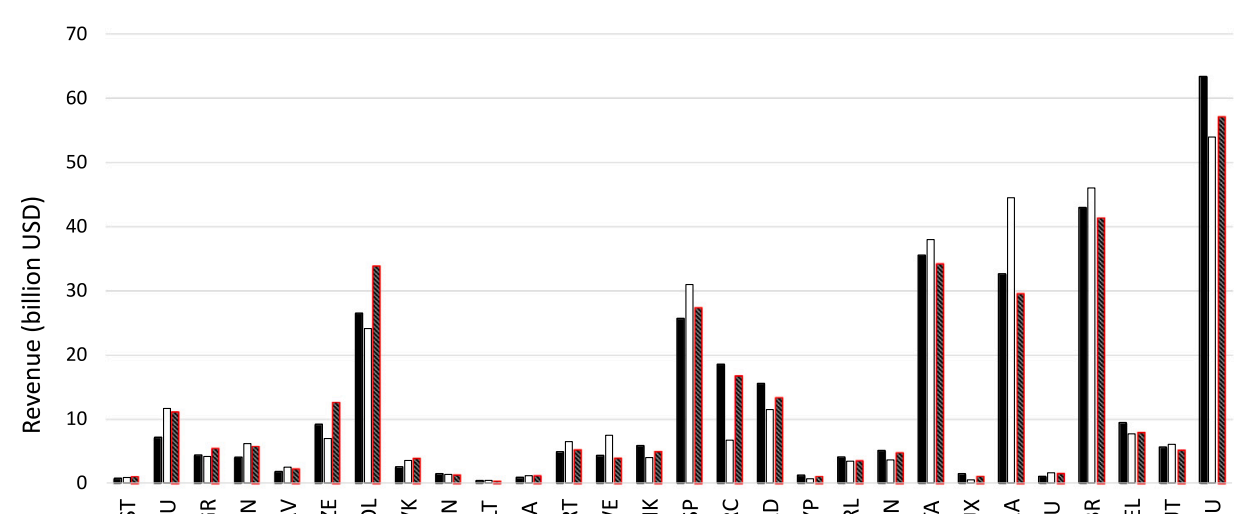

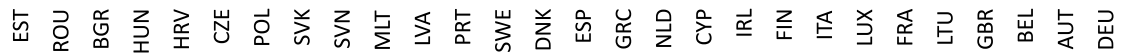

- Full ETS \& Emissions $\quad$ Full ETS \& Per-capita \$ Full ETS \& Phase IV rules + emissions

Panel (b): Carbon pricing revenue allocation to countries under Full ETS

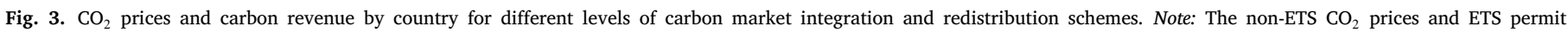
prices are similar across the redistribution schemes. Panel (a) only displays $\mathrm{CO}_{2}$ prices for the redistribution scheme Emissions.

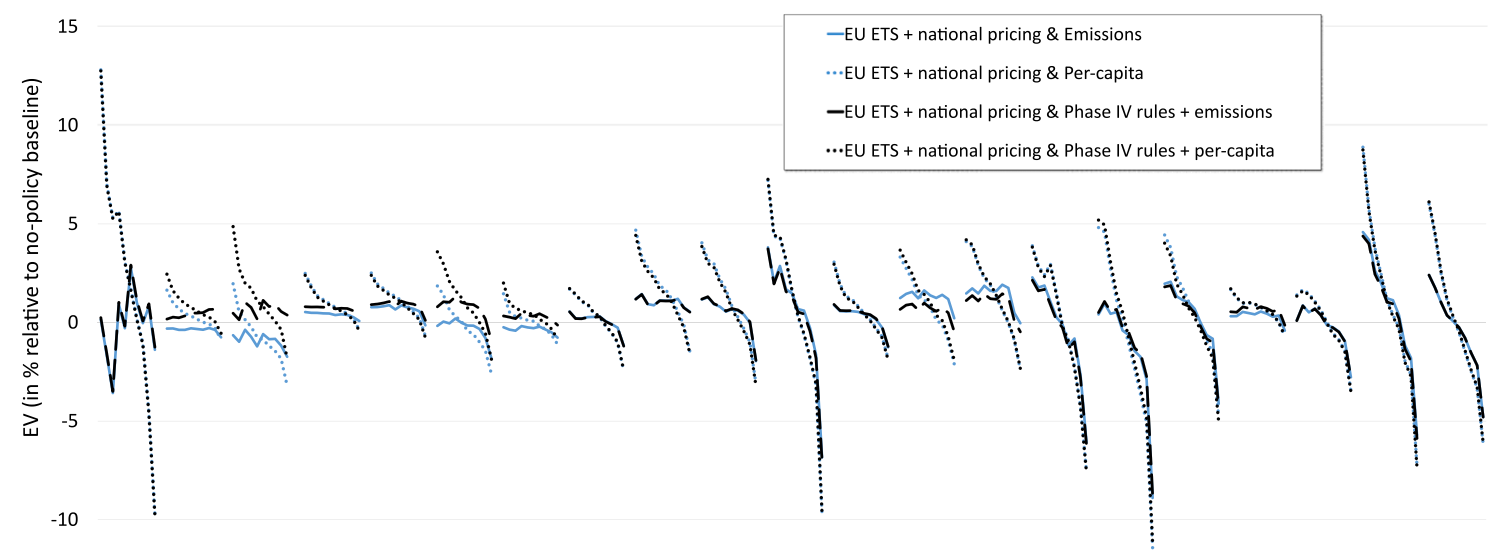

$-15$

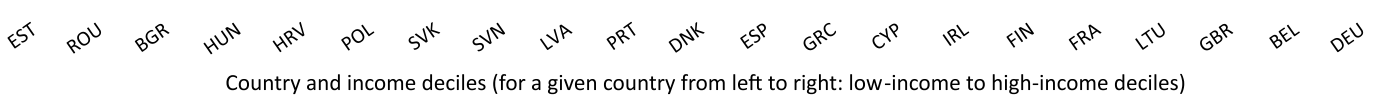

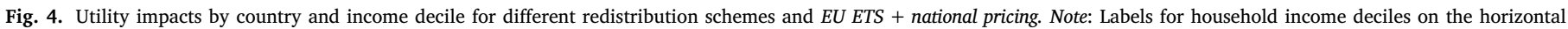
axis are suppressed for readability. 


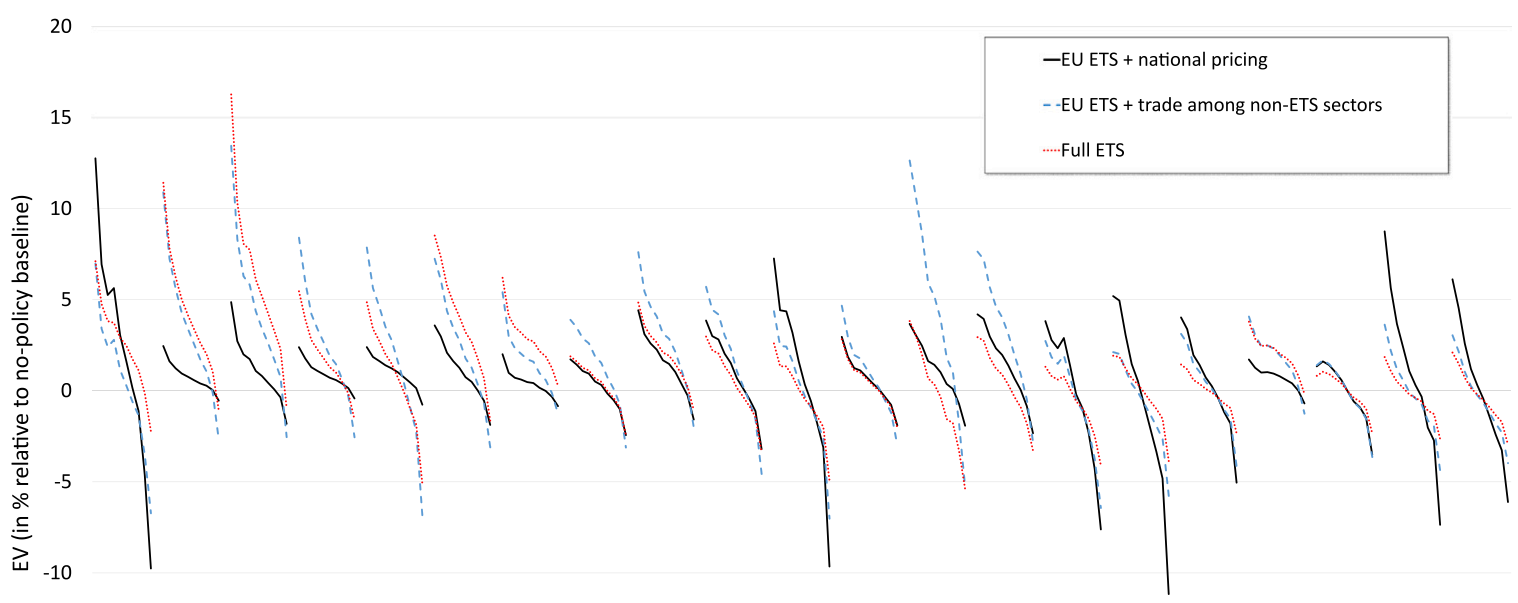

$-15$

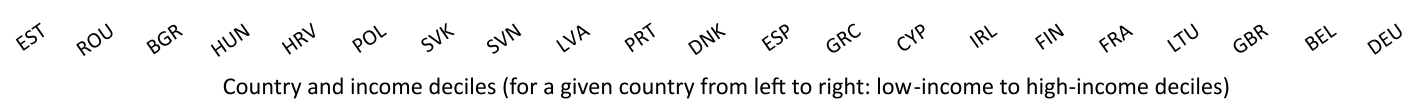

Panel (a): for different levels of carbon market integration (assuming Phase IV rules + per-capita redistribution)

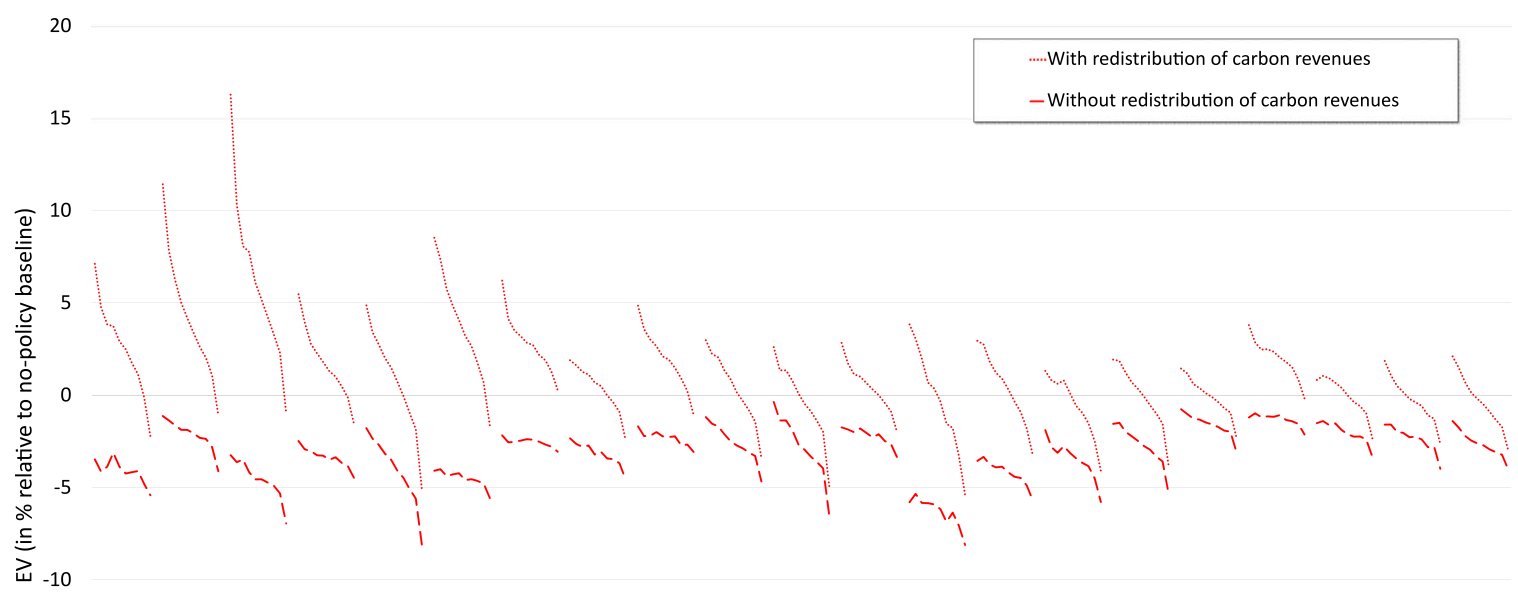

$-15$

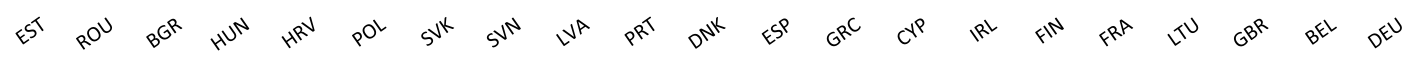

$$
\begin{aligned}
& \text { Country and income deciles (for a given country from left to right: low-income to high-income deciles) }
\end{aligned}
$$

Panel (b): with and without carbon revenue redistribution (assuming Full ETS E Phase IV rules + per-capita)

Fig. 5. Utility impacts by country and household decile.

Overall, it is straightforward to see that the progressive nature of the combined utility impact when ignoring revenue recycling is clearly dominated by the sources-side effects. ${ }^{23}$

Panel (b) of Fig. 6 provides the same decomposition for a different level of $\mathrm{CO}_{2}$ price harmonization. Comparing Panels (a) and (b) of

\footnotetext{
23 We note that our result that distributional impacts when ignoring carbon revenue recycling are progressive depends on the assumption that pre-existing transfers are constant (in terms of national consumption price indices or adjusted to inflation). We believe that it is reasonable to assume that policy makers adjust these pre-existing transfers to inflation. When transfers are indexed to wages, Fig. C.3 of Appendix C shows that results are different. Comparison to Figs. C. 3 and 6 shows that the progressivity of within-country household incidence is weaker in most countries and even disappears for some countries.
}

Fig. 6 underscores the general insight that distributional effects change across $\mathrm{CO}_{2}$ price harmonization scenarios as market prices of consumption goods (affecting household consumption costs) and factors of production (affecting household income) change. Thus, the overall distribution of climate policy costs within countries is not only affected by the level of $\mathrm{CO}_{2}$ price revenues to be redistributed, but is also crucially determined by the market effects on the costs of consumption and, in particular, income.

\section{Harmonizing $\mathrm{CO}_{2}$ prices in the $\mathrm{EU}$ : A social welfare assessment}

\subsection{Atkinson welfare function}

This section evaluates the different $\mathrm{CO}_{2}$ price harmonization options in terms of a social welfare function approach which integrates 
2

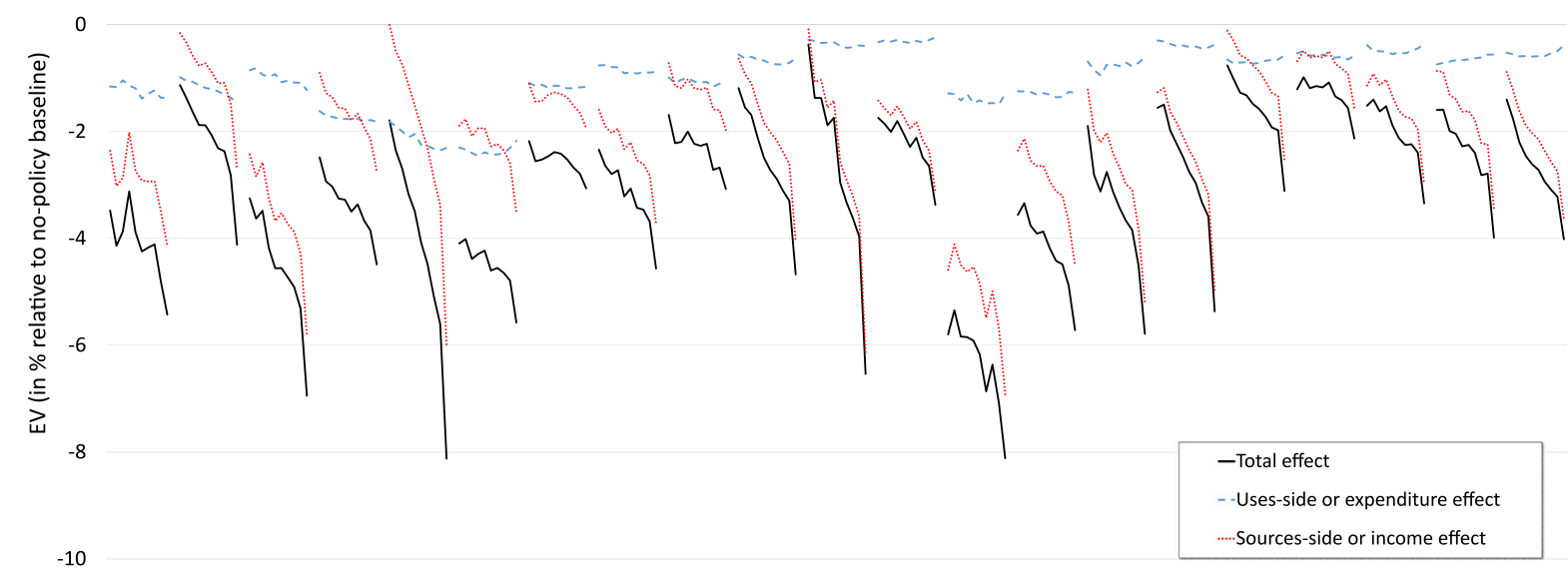

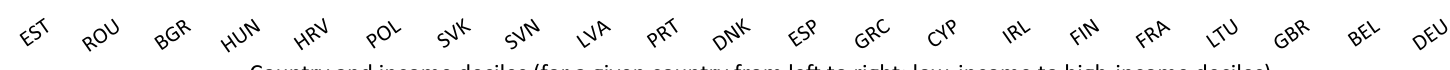
Country and income deciles (for a given country from left to right: low-income to high-income deciles)

Panel (a): Full ETS

5

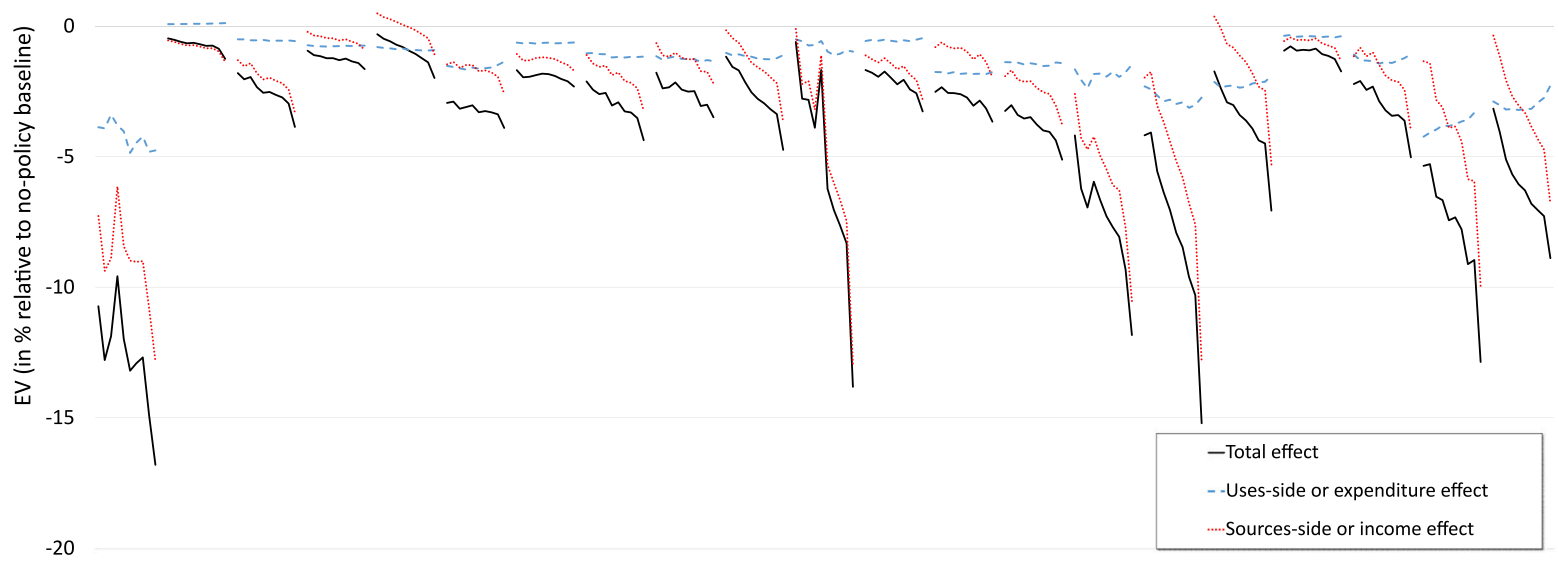

$-20$

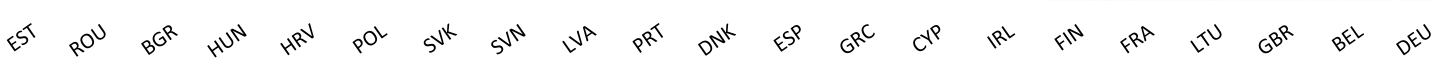

Country and income deciles (for a given country from left to right: low-income to high-income deciles)

Panel (b): EU ETS + national pricing

Fig. 6. Decomposition of utility impacts by country and household income decile into uses- and sources-side effects.

efficiency and equity perspectives. For this, we use the Atkinson 1970 index of inequality, $A_{\varepsilon}$, which for the given context is defined as follows:

$A_{\varepsilon}=1-\frac{1}{\Gamma}\left[\frac{\sum_{r, h \in H_{r}} \frac{\mathcal{P}_{r}}{\left|H_{r}\right|}\left(Y_{h, r}^{0, P P P}\left(1+E V_{h, r} / Y_{h, r}^{0}\right)\right)^{1-\varepsilon}}{\sum_{r} \mathcal{P}_{r}}\right]^{\frac{1}{1-\varepsilon}}$.

$H_{r}$ defines the region-dependent set of representative households in the model and $\left|H_{r}\right|$ its cardinality (see Table 1 ). $\Gamma$ denotes mean money-metric utility in PPP:

$\Gamma=\frac{\sum_{r, h \in H_{r}} \frac{\mathcal{P}_{r}}{\left|H_{r}\right|}\left(Y_{h, r}^{0, P P P}\left(1+E V_{h, r} / Y_{h, r}^{0}\right)\right)}{\sum_{r} \mathcal{P}_{r}}$, where $Y_{h r}^{0}$ is the per-capita money-metric utility of household $h$ in country $r$ in the baseline, $Y_{h, r}^{0, P P P}$ the baseline per-capita money-metric utility adjusted for the purchasing power of country $r, E V_{h, r}$ the equivalent variation due to the policy intervention, $\mathcal{P}_{r}$ the population of country $r$, and $\varepsilon$ the Atkinson index's parameter of inequality aversion. Social welfare $\mathcal{W}$ is then defined as

$\mathcal{W}=\Gamma \times\left(1-A_{\varepsilon}\right)=\left[\frac{\sum_{h, r \in H_{r}} \frac{\mathcal{P}_{r}}{\left|H_{r}\right|}\left(Y_{h, r}^{0, P P P}\left(1+E V_{h, r} / Y_{h, r}^{0}\right)\right)^{1-\varepsilon}}{\sum_{r} \mathcal{P}_{r}}\right]^{\frac{1}{1-\varepsilon}}$

\subsection{An equity-driven double dividend from carbon pricing?}

Fig. 7 reports the percentage change in $\mathcal{W}$, relative to a "no-climate policy" baseline, for different degrees of social inequality aversion $\varepsilon$ 
1.5

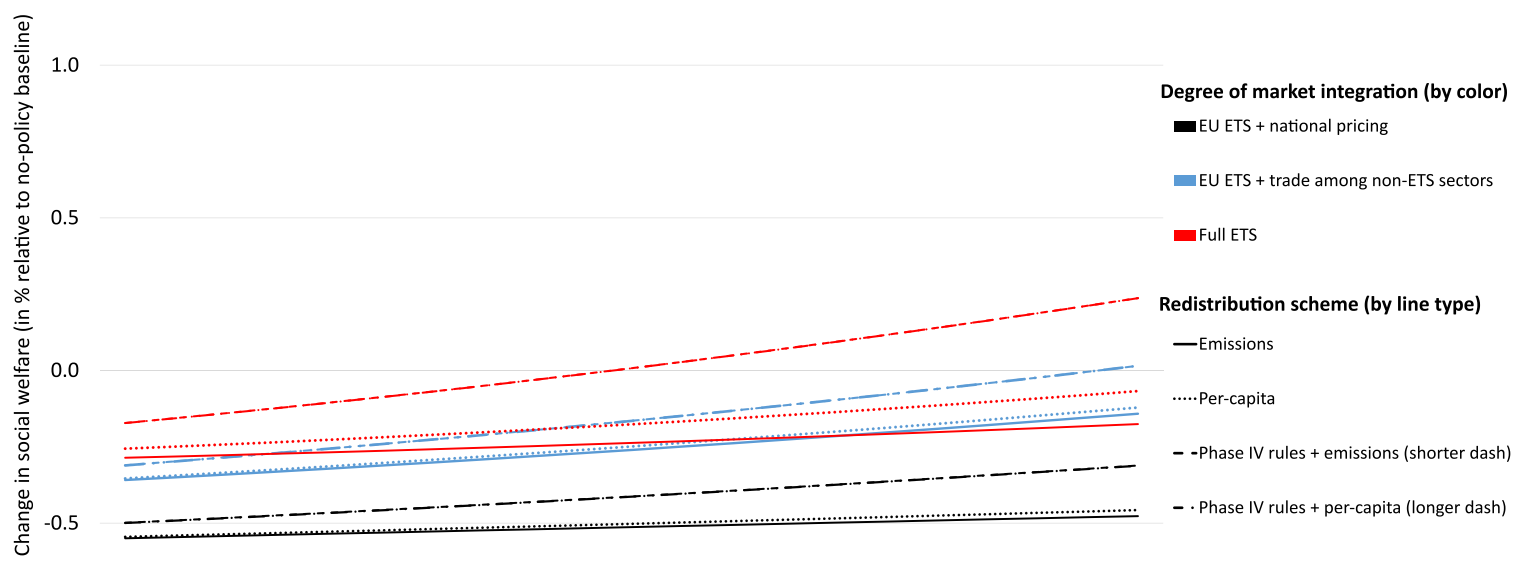

$-1.0$

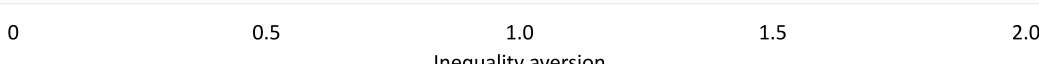

Panel (a): based on between-country inequality only

1.5

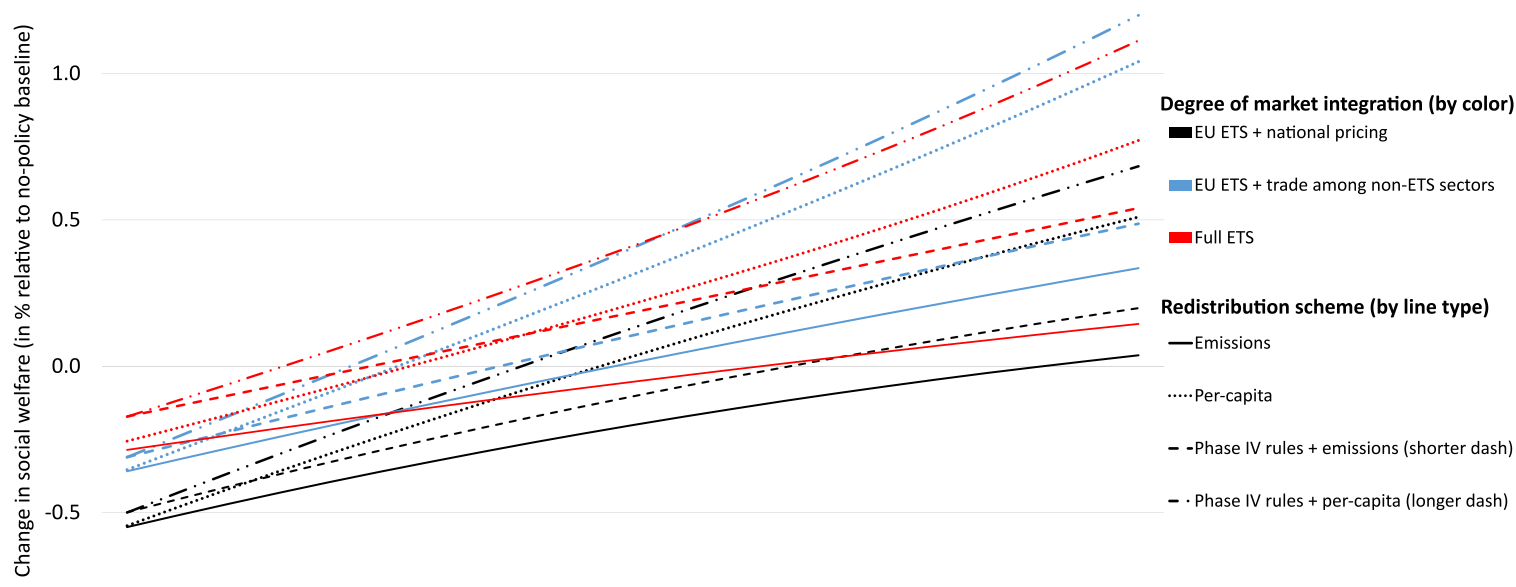

$-1.0$

0.5

1.0

1.5

2.0

Inequality aversion

Panel (b): based on between- and within-country inequality

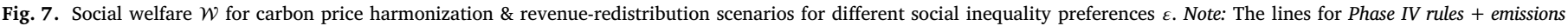
and Phase IV rules + per-capita overlap in Panel (a).

and for the different $\mathrm{CO}_{2}$ price harmonization scenarios and redistribution rules considered above. Several important insights emerge.

First, in the case of no inequality aversion $(\varepsilon=0)$, the social welfare function is reduced to the average PPP-adjusted EV. ${ }^{24}$ The results in this case agree with the economic intuition that an enhanced level of

24 While not including normative arguments about inequality aversion, this still differs from the analysis of EV based on EU-wide consumption budget and consumer prices: Since it measures utility in purchasing power parity, average
$\mathrm{CO}_{2}$ price harmonization increases the purchasing power of consumers through shared efficiency gains from the carbon market. Second, for a given level of $\mathrm{CO}_{2}$ price harmonization and independent of the degree of social inequality aversion, distributing carbon revenues from the EU ETS according to Phase IV rules is the preferred option. This reflects that lower-income EU countries are "overcompensated" under Phase IV

money-metric utility is not invariant to transfers of money between countries in which that money has different purchasing power. 
rules while the impacts on consumption utility for higher-income EU countries are mostly unaffected by different redistribution rules. Third, for "realistic" degrees of inequality aversion (for example, around 1.2, see Layard et al., 2008, for a discussion of empirical estimates) how harmonized (EU ETS + trade among non-ETS sectors or Full ETS) and current (EU ETS + national pricing) $\mathrm{CO}_{2}$ pricing schemes compare to one another does not depend on the choice of the redistribution rule. EU ETS + trade among non-ETS sectors and Full ETS both generate higher social welfare outcomes, and their advantage relative to EU ETS + national pricing increases with $\varepsilon$. Fourth, assuming a social welfare function with plausible levels of inequality aversion, well-designed climate policy combined with appropriate revenue redistribution may even yield positive social welfare changes compared to a "no-climate policy" baseline. For $\varepsilon=1$ and higher-which is well within the range of empirically plausible estimates-this is achieved for full carbon market integration (Full ETS) if the carbon revenues from allowance auctioning are redistributed according to Phase IV rules.

Panel (a) of Fig. 7 provides insights into the social welfare ranking of the different policy options when social equity concerns are mainly over the differential mean impacts across countries. This perspective is particularly appropriate if one assumes that countries participating in the EU ETS strive to keep the distribution of policy costs within countries neutral (e.g., by means of appropriate lump-sum transfers). The previous analysis has shown, however, that carbon pricing with revenue recycling according to the analyzed rules will bring about substantially heterogeneous impacts within countries at the household level. Panel (b) of Fig. 7 thus reports a version of social welfare $\mathcal{W}$ which acknowledges both inter-regional and within-country inequality. The main insight is that the per-capita redistribution rules, which create highly progressive impacts (see Fig. 5), imply positive social welfare changes compared to a "no-climate policy" baseline if the redistribution of carbon revenues within countries is the same percapita. Interestingly, in this case, the advantage of Full ETS over EU ETS + Trade among non-ETS sectors vanishes for realistic levels of inequality aversion.

Overall, we find that increasing $\mathrm{CO}_{2}$ price harmonization beyond what is implied by current EU climate policy-as reflected by $E U$ ETS + national pricing-leads to social welfare gains regardless of the redistribution rules for carbon revenue recycling. These gains increase when higher levels of inequality aversion are assumed. Assuming that social inequality aversion is within the range of empirically plausible estimates, sufficiently harmonized EU carbon markets combined with Phase IV recycling programs even imply net welfare gains from climate policy. Remarkably, these gains do not yet include the potential benefits from averted climate damages, which points in the direction of an equity-driven strong double dividend from carbon pricing. ${ }^{25}$

\section{Concluding remarks}

Harmonizing $\mathrm{CO}_{2}$ prices by increasing the regional and sectoral scope of carbon markets is widely advocated by economists as a means to reduce abatement costs of meeting a given environmental target. Despite the importance for political and social acceptance of carbon pricing policies, little research has examined the distributional implications of such carbon market integration. This paper aims to fill this gap by analyzing the efficiency and distributional impacts of increased $\mathrm{CO}_{2}$ price harmonization in the EU economy. We examine three degrees of

\footnotetext{
25 Such an equity-driven double-dividend is driven by the vast redistribution from high-income to low-income deciles by means of lump-sum revenue recycling. While it is arguably desirable for policymakers to avoid regressive outcomes, and while countries have the financial resources to steer against regressive outcomes by appropriate redistribution of carbon revenues, it is questionable to what extent governments are interested in creating distinctively progressive outcomes.
}

$\mathrm{CO}_{2}$ market integration, which can be interpreted as stages in a likely (longer-term) path for EU climate policy, ranging from the current policy situation of segmented carbon markets as represented by the EU ETS and country-specific targets for non-ETS sectors, to an intermediate case of two emissions trading systems, to an eventually fully integrated EU carbon market. We analyze both the effects of $\mathrm{CO}_{2}$ price harmonization and alternative ways to redistribute carbon revenues between and within EU countries.

We find that harmonizing $\mathrm{CO}_{2}$ prices across $\mathrm{EU}$ countries and sectors yields efficiency gains at the EU level compared to the current fragmented setting of European carbon markets. As the level of gains increases with the degree of $\mathrm{CO}_{2}$ market integration, future EU climate should work to expand the sectoral scope of the EU ETS or link the EU ETS to newly established emissions trading schemes that are likely to be introduced in the next few years. Such policy designs should in any case be accompanied by measures that address the uneven distributional effects between and within countries. Our analysis clearly shows the potentially large uneven impacts from carbon pricing between and within EU countries. Importantly, however, it is possible to design carbon pricing policies, including the future integration of carbon markets in Europe, in a way that effectively addresses unintended distributional consequences. For example, we find that efficiency gains from $\mathrm{CO}_{2}$ price harmonization flow disproportionately to low-income EU countries when redistribution is based on the rules currently in place in phase four of the EU ETS. Thus, to the extent that equity concerns in EU climate policy are about protecting low-income countries from bearing disproportionately large economic burdens, we find no pronounced conflict between efficiency and equity.

Concerning the within-country effects between household income deciles, we find that the impact of carbon pricing is progressive in most EU countries. We find that progressivity is more pronounced when percapita based schemes are used to distribute carbon revenues within a country and that such schemes entail large utility gains for lowincome households in all countries. Importantly, we find that even without redistribution of carbon revenues, the impacts from carbon pricing are non-regressive within most EU countries. At the core of this result is the progressivity of the sources-side effects of (capital and labor) income which we find to be clearly progressive for almost all EU countries, and which dominate the regressive uses-side of income effects. While our paper provides the first evidence from a cross-country European assessment, this mirrors the findings of previous studies of carbon pricing policies in the U.S. context (Rausch et al., 2011; Goulder et al., 2019). If the policy goal is to avoid regressive outcomes within a country, this implies that recycling only a portion of carbon revenues on a "uniform" per-capita basis might be sufficient to address distributional concerns, while the remaining carbon revenues could be used in other productive ways (for example, by promoting knowledge creation and diffusion related to climate-friendly technologies or lowering distortionary income taxes). Finally, we adopt a European social welfare perspective which integrates perspectives on efficiency and social inequality (aversion) with respect to between- and withincountry impacts. We find that combining $\mathrm{CO}_{2}$ price harmonization with adequate redistribution rules can have positive social welfare effects compared to a "no-climate policy" benchmark when social inequality aversion is strong. Notably, these gains do not include potential benefits from averted climate damages, suggesting an equity-driven strong double-dividend from carbon pricing in the EU.

\section{Funding}

The research leading to this paper has profited from project work financed under "Macro modelling with micro data for distributional and employment assessment (JRC/SVQ/2019/MVP/2658)" by the Joint Research Center of the European Union. 
Table A.1

Model variables.

\begin{tabular}{ll}
\hline Name & Description \\
\hline Activity levels & \\
$G_{r}$ & Public consumption index in region $r$ \\
$C_{h, r}$ & Consumption index of household $h$ in region $r$ \\
$I_{r}$ & Investment consumption index in region $r$ \\
$Y_{i, r}$ & Production index of sector $i$ in region $r$ \\
$A_{i, g, r}$ & Armington index of commodity $i$ in region $r$ \\
$T_{i}$ & Production index of international transport service $i$ \\
$P r i c e s$ & \\
$P Y_{i, r}$ & Domestic commodity $i$ output price in region $r$ \\
$P A_{i, g, r}$ & Armington price of commodity $i$ in region $r$ \\
$P T_{i}$ & Price index international transport service $i$ \\
$P L_{r}$ & Wage rate in region $r$ \\
$P K_{r}$ & Capital rental rate in region $r$ \\
$P C_{h, r}$ & Household specific cost of consumption in region $r$ \\
$P G_{r}$ & Public consumption price index in region $r$ \\
$P I_{r}$ & Investment consumption price index in region $r$ \\
$P C O 2_{c p s}$ & Price of CO ${ }_{2}$ emissions in carbon pricing scheme $c p s$ \\
$E x p e n d i t u r e ~ b u d g e t s$ & \\
$E X P_{h, r}^{C}$ & Expenditure budget of household $h$ in region $r$ \\
$E X P_{r}^{G}$ & Public income in region $r$ \\
Auxiliary variables & \\
$\mathrm{CPI}_{r}$ & Consumption price index in region $r$ \\
$\mathrm{REVREC}_{r}$ & Recycling of revenue from carbon pricing policies in region $r$ \\
$\mathrm{PUBCLS}_{p c l, r}$ & Public closure for achieving constant real public spending \\
& in each region $r$ across scenarios \\
\hline &
\end{tabular}

\section{CRediT authorship contribution statement}

Florian Landis: Conceptualization, Methodology, Software, Formal analysis, Data curation, Writing - original draft, Writing - review \& editing, Visualization, Project administration. Gustav Fredriksson: Methodology, Software, Data curation, Writing - review \& editing, Visualization. Sebastian Rausch: Conceptualization, Methodology, Writing - original draft, Writing - review \& editing, Visualization.

\section{Declaration of competing interest}

The authors declare that they have no known competing financial interests or personal relationships that could have appeared to influence the work reported in this paper.

\section{Acknowledgments}

The authors thank Toon Vandyck and two anonymous reviewers for their helpful comments, and Dario Küng for excellent research assistance. The responsibility for all conclusions and potential errors lies solely with the authors.

\section{Appendix A. Algebraic model formulation}

The general equilibrium model is formulated as a mixed complementarity program (Mathiesen, 1985; Rutherford, 1995) using MPS/GE (Rutherford, 1999) in GAMS. Mixed complementarity programs "pair" nonlinear inequalities with variables and require the inequalities to hold with equality as long as the paired variables are not at their bounds. CGE models consist of zero-profit conditions for all economic sectors in the model that are complementary ("paired") with the activity levels of those sectors. ${ }^{26}$ market clearing conditions for all goods in the model that are complementary with market prices of those

26 Complementarity allows for the special case where unit costs exceed unit revenue but then require the activity level of the sector to be zero.
Table A.2

Parameters for baseline calibration of the model.

\begin{tabular}{|c|c|}
\hline Name & Description \\
\hline \multicolumn{2}{|l|}{ Price levels } \\
\hline$\overline{p c}_{h, r}$ & Baseline cost of consumption of household $h$ in region $r$ \\
\hline$\overline{p g}_{r}$ & Baseline price index of public expenditure in region $r$ \\
\hline$\overline{\operatorname{pinv}}_{r}$ & Baseline cost of investment activity in region $r$ \\
\hline$\overline{p y}_{i, r}$ & Baseline price of output by industry $i$ in region $r$ \\
\hline$\overline{p a}_{i, g, r}$ & Baseline price of Armington good in region $r$ \\
\hline$\overline{p t}_{i}$ & Baseline price of international transport services \\
\hline$\overline{p f}_{f, r}$ & Baseline price of mobile factor $f$ in region $r$ \\
\hline$\overline{p f s}_{\mathrm{res}, i, r}$ & Baseline price of specific resource for industry $i$ in region $r$ \\
\hline$\overline{p c o 2}_{c p s}$ & Baseline price of carbon emissions in carbon pricing scheme $c p s$ \\
\hline \multicolumn{2}{|l|}{ Tax rates } \\
\hline$t f_{f, i, r}$ & Tax on demand for production factor $f$ by industry $i$ in region $r$ \\
\hline$t i_{i, g, r}$ & Tax on demand for intermediate input $i$ by sector $g$ in region $r$ \\
\hline$t e_{i, r, s}$ & Tax rate on exports of commodity $i$ from region $r$ to region $s$ \\
\hline$t m_{i, r, s}$ & Tariff rate on imports of commodity $i$ from region $r$ into region $s$ \\
\hline \multicolumn{2}{|c|}{ Value flows and quantities } \\
\hline $\bar{F}_{f, h, r}$ & $\begin{array}{l}\text { Benchmark provision of mobile factor } f \text { by household } h \\
\text { in region } r\end{array}$ \\
\hline$\overline{F S}_{\mathrm{res}, i, h, r}$ & $\begin{array}{l}\text { Benchmark provision of specific resources to industry } i \text { by } \\
\text { household } h \text { in region } r\end{array}$ \\
\hline $\bar{I}_{h, r}$ & Benchmark demand for investment by household $h$ in region $r$ \\
\hline $\bar{E}_{c p s, r}$ & $\begin{array}{l}\text { Amount of emission permits sold by region } r \text { under carbon } \\
\text { pricing scheme } c p s\end{array}$ \\
\hline $\bar{C}_{h, r}$ & $\begin{array}{l}\text { Benchmark demand for aggregated consumption by } \\
\text { household } h \text { in region } r\end{array}$ \\
\hline$\overline{\text { htax }}_{h, r}$ & $\begin{array}{l}\text { Benchmark transfers from household } h \text { to government in region } r \\
\text { Benchmark value of the balance of trade by region } r\end{array}$ \\
\hline$\overline{E X P^{G}}{ }_{r}$ & Benchmark public expenditure by the government in region $r$ \\
\hline${\overline{E X P^{C}}}_{h, r}$ & Benchmark expenditure by household $h$ in region $r$ \\
\hline
\end{tabular}

goods ${ }^{27}$ and budget balance conditions for all representative agents in the model that are complementary to the agents' expenditure budget. In the following description of the system of inequalities that makes up the model, we use the $\perp$ operator to indicate complementarity between equilibrium conditions and variables. Model variables and parameters are defined in Tables A.1, A.2, A.3, and A.4.

Zero-profit conditions are of the form "unit cost $\geq$ unit revenue":

$$
\begin{aligned}
& c_{h, r}^{C} \geq \frac{P C_{h, r}}{\overline{p c}_{h, r}} \quad \perp C_{h, r} \geq 0 \quad \forall r \quad \text { (A.1) }
\end{aligned}
$$

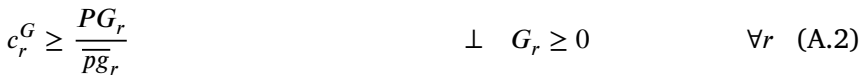

$$
\begin{aligned}
& c_{r}^{I} \geq \frac{P I N V_{r}}{\overline{\operatorname{pinv}}_{r}} \quad \perp I_{r} \geq 0 \quad \forall r \text { (A.3) } \\
& c_{i, r}^{Y} \geq \frac{P Y_{i, r}}{\overline{p y}_{i, r}} \quad \perp Y_{i, r} \geq 0 \quad \forall i, r \quad \text { (A.4) } \\
& c_{i, g, r}^{A} \geq \frac{P A_{i, g, r}}{\overline{p a}_{i, g, r}} \quad \perp \quad A_{i, g, r} \geq 0 \quad \forall i, g \neq \mathrm{C}, r \quad \text { (A.5) } \\
& c_{i, c, r}^{A} \geq \frac{P A_{i, \mathrm{C}, r}}{\overline{p a}_{i, \mathrm{C}, r}} \cdot\left(1-\mathrm{PUBCLS}_{\mathrm{vat}, r}\right) \quad \perp \quad A_{i, \mathrm{C}, r} \geq 0 \quad \forall i, r \quad \text { (A.6) } \\
& c_{i}^{T} \geq \frac{P T_{i}}{\overline{p t}_{i}} \quad \perp T_{i} \geq 0
\end{aligned}
$$

where $c^{V}$ denotes the unit cost function of sector with activity level $V$ and unit revenue is the price $P$ of the unique good produced by the sector.

According to the nesting structures shown in Fig. A.3, the unit cost functions for consumers, government, and the investment activity are

27 Here, complementarity allows for excess supply in the special case where the price of the market good is zero. 


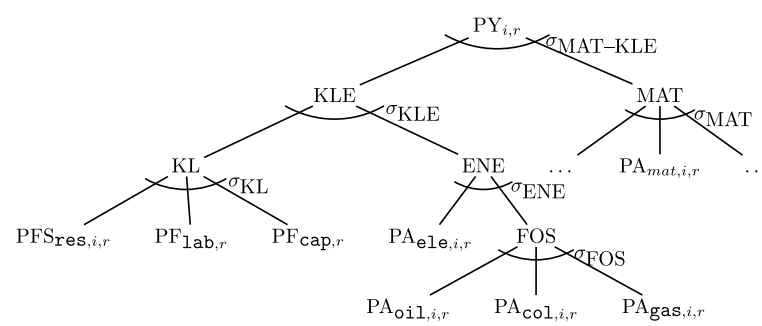

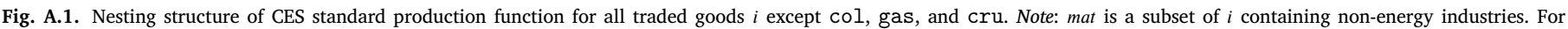
elasticities of substitution, see Table A.4.

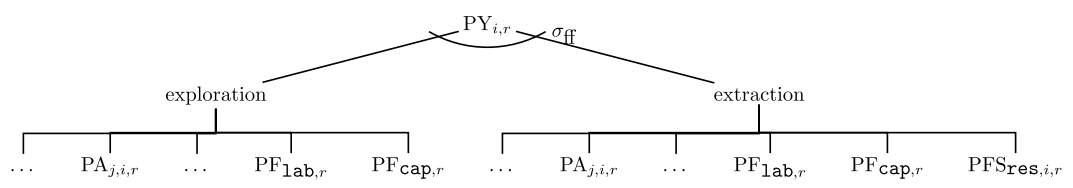

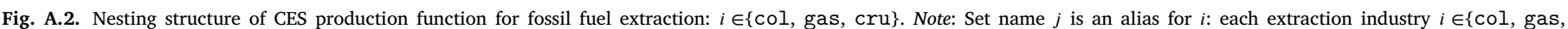
$\mathrm{cru}$ \} potentially demands intermediate inputs $\mathrm{PA}_{j, i, r}$ from all industries $j$. For elasticities of substitution, see Table A.4.
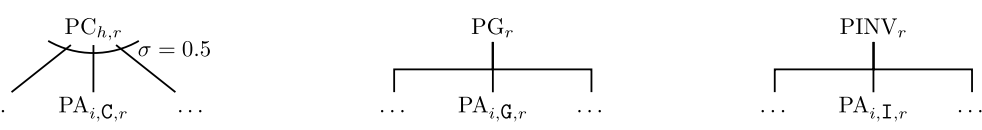

Fig. A.3. Nesting structures of CES production functions representing final demand: household consumption, government spending, and investment.
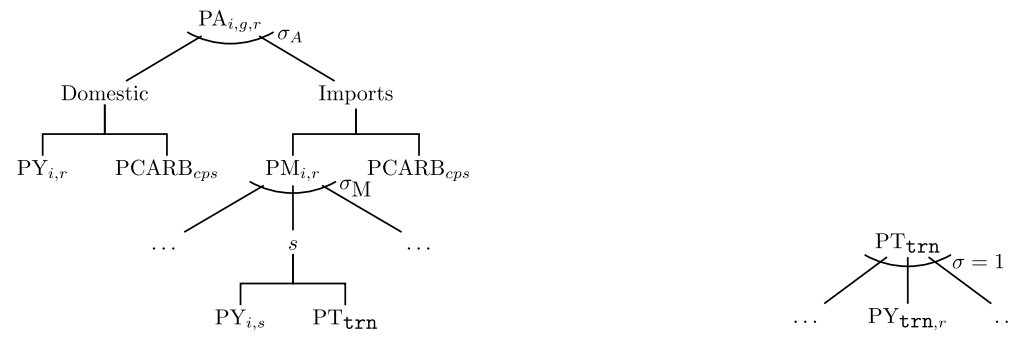

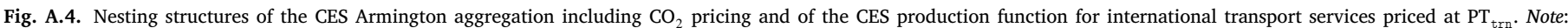

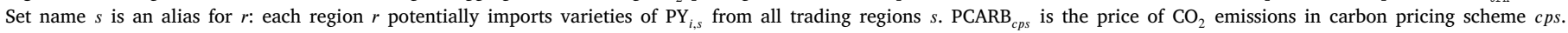

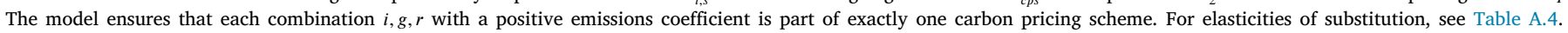

defined $\mathrm{as}^{28}$ :

$$
\begin{aligned}
c_{h, r}^{C} & :=\left[\sum_{i \in I} \theta_{i}^{C_{h, r}}\left(\frac{P A_{i, \mathrm{C}, r}}{\overline{p a}_{i, \mathrm{C}, r}}\right)^{1-0.5}\right]^{\frac{1}{1-0.5}} \quad \forall h \in H_{r} \\
c_{r}^{G} & :=\sum_{i \in I} \theta_{i}^{G_{r}} \frac{P A_{i, \mathrm{G}, r}}{\overline{p a}_{i, \mathrm{G}, r}} \\
c_{r}^{I} & :=\sum_{i \in I} \theta_{i}^{I_{r}} \frac{P A_{i, \mathrm{I}, r}}{\overline{p a}_{i, \mathrm{I}, r}}
\end{aligned}
$$

28 Prices denoted with an overline generally refer to baseline prices observed in the benchmark equilibrium. $\theta_{S N}^{N}$, where $S N$ is a CES subnest of CES nest $N$, refers to the share of subnest $S N$ in total expenditures for CES nest $N$, and $\theta_{i}^{N}$ refers to the share of input $i$ contributing to total expenditures for CES nest $N$.
Unit cost functions for all production activities except resource extraction (i.e., $i \in I \backslash\{\mathrm{col}$, gas, cru $\}$ ) are given as

$$
c_{i, r}^{Y}:=\left[\theta_{K L E}^{Y_{i, r}}\left(c_{i, r}^{K L E}\right)^{1-\sigma^{t o p}}+\theta_{M A T}^{Y_{i, r}}\left(c_{i, r}^{M A T}\right)^{1-\sigma^{t o p}}\right]^{\frac{1}{1-\sigma^{t o p}}},
$$

where

$$
\begin{aligned}
& c_{i, r}^{M A T}:=\left[\sum_{j \in m a t} \theta_{j}^{M A T_{i, r}}\left(\frac{P A_{j, i, r}}{\overline{p a}_{j, i, r}}\right)^{1-\sigma^{m a t}}\right]^{\frac{1}{1-\sigma^{m a t}}} \\
& c_{i, r}^{K L E}:=\left[\theta_{K L}^{K L E_{i, r}}\left(c_{i, r}^{K L}\right)^{1-\sigma^{k l e}}+\theta_{E N E}^{K L E_{i, r}}\left(c_{i, r}^{E N E}\right)^{1-\sigma^{k l e}}\right]^{\frac{1}{1-\sigma^{k l e}}} \\
& c_{i, r}^{K L}:=\left[\theta_{\mathrm{lab}}^{K L_{i, r}}\left(\frac{P F_{\mathrm{lab}, r}}{\overline{p f}_{\mathrm{lab}, r}}\right)^{1-\sigma^{k l}}+\theta_{\mathrm{cap}}^{K L_{i, r}}\left(\frac{P F_{\mathrm{cap}, r}}{\overline{p f}_{\mathrm{cap}, r}}\right)^{1-\sigma^{k l}}\right. \\
& \left.+\theta_{\mathrm{res}}^{K L_{i, r}}\left(\frac{P F S_{\mathrm{res}, i, r}}{\overline{p f s}_{\mathrm{res}, i, r}}\right)^{1-\sigma^{k l}}\right]^{\frac{1}{1-\sigma^{k l}}}
\end{aligned}
$$


Table A.3

Expenditure shares for calibration of the model.

\begin{tabular}{|c|c|}
\hline Name & Description \\
\hline$\theta_{i}^{C_{h, r}}$ & Expenditure share of commodity $i$ in total consumption expenditure \\
\hline$\theta_{i}^{G_{r}}$ & Expenditure share of commodity $i$ public expenditure \\
\hline$\theta_{i}^{I_{r}}$ & Expenditure share of commodity $i$ investment activity \\
\hline$\theta_{K L E}^{Y_{i, r}}$ & $\begin{array}{l}\text { Expenditure share of } K L E \text {-nest in total expenditure of industry } i \\
\text { in region } r\end{array}$ \\
\hline$\theta_{M A T}^{Y_{i, r}}$ & $\begin{array}{l}\text { Expenditure share of } M A T \text {-nest in total expenditure of industry } i \\
\text { in region } r\end{array}$ \\
\hline$\theta_{j}^{M A T_{i, r}}$ & $\begin{array}{l}\text { Expenditure share of input } j \text { to the } M A T \text { subnest of industry } i \text { in } \\
\text { region } r\end{array}$ \\
\hline$\theta_{K L}^{K L E_{i, r}}$ & $\begin{array}{l}\text { Expenditure share of } K L \text { subnest in the } K L E \text {-nest of industry } i \text { in } \\
\text { region } r\end{array}$ \\
\hline$\theta_{E N E}^{K L E_{i, r}}$ & $\begin{array}{l}\text { Expenditure share of } E N E \text { subnest in the } K L E \text {-nest of industry } i \\
\text { in region } r\end{array}$ \\
\hline$\theta_{f}^{K L_{i, r}}$ & Expenditure share of factor $f$ in the $K L$-nest of industry $i$ in region $r$ \\
\hline$\theta_{\mathrm{ele}}^{E N E_{i, r}}$ & $\begin{array}{l}\text { Expenditure share of electricity in the } E N E \text {-nest of industry } i \text { in } \\
\text { region } r\end{array}$ \\
\hline$\theta_{F O S}^{E N E_{i, r}}$ & $\begin{array}{l}\text { Expenditure share of FOS subnest in the } E N E \text {-nest of industry } i \text { in } \\
\text { region } r\end{array}$ \\
\hline$\theta_{i}^{F O S_{i, r}}$ & $\begin{array}{l}\text { Expenditure share of commodity } i \text { in the } F O S \text {-nest of industry } i \text { in } \\
\text { region } r\end{array}$ \\
\hline$\theta_{E X P}^{Y_{i, r}}$ & $\begin{array}{l}\text { Expenditure share of } E X P \text {-nest in total expenditure of industry } i \text { in } \\
\text { region } r\end{array}$ \\
\hline$\theta_{E X T}^{Y_{i, r}}$ & $\begin{array}{l}\text { Expenditure share of } E X T \text {-nest in total expenditure of industry } i \text { in } \\
\text { region } r\end{array}$ \\
\hline$\theta_{j}^{E X P_{i, r}}$ & $\begin{array}{l}\text { Expenditure share of commodity } j \text { in the } E X P \text {-nest of industry } i \text { in } \\
\text { region } r\end{array}$ \\
\hline$\theta_{f}^{E X P_{i, r}}$ & $\begin{array}{l}\text { Expenditure share of factor } f \text { in the } E X P \text {-nest of industry } i \text { in region } \\
r\end{array}$ \\
\hline$\theta_{j}^{E X T_{i, r}}$ & $\begin{array}{l}\text { Expenditure share of commodity } j \text { in the } E X T \text {-nest of industry } i \\
\text { in region } r\end{array}$ \\
\hline$\theta_{f}^{E X T_{i, r}}$ & $\begin{array}{l}\text { Expenditure share of factor } f \text { in the } E X T \text {-nest of industry } i \text { in region } \\
r\end{array}$ \\
\hline$\theta_{A Y}^{A_{i, g, r}}$ & $\begin{array}{l}\text { Expenditure share of domestic nest } A Y \text { in total expenditure for } \\
\text { Armington good } i \text { by sector } g \text { in region } r\end{array}$ \\
\hline$\theta_{M}^{A_{i, g, r}}$ & $\begin{array}{l}\text { Expenditure share of imports nest } M \text { in total expenditure for } \\
\text { Armington good } i \text { by sector } g \text { in region } r\end{array}$ \\
\hline$\theta_{Y}^{A Y_{i, g, r}}$ & $\begin{array}{l}\text { Expenditure share of commodity cost in nest } A Y \text { of Armington good } i \\
\text { by sector } g \text { in region } r\end{array}$ \\
\hline$\theta_{c p s}^{A Y_{i, g, r}}$ & $\begin{array}{l}\text { Expenditure share of carbon price of carbon pricing scheme } c p s \\
\text { in nest } A Y \text { of Armington good } i \text { by sector } g \text { in region } r\end{array}$ \\
\hline$\theta_{M}^{A M_{i, g, r}}$ & $\begin{array}{l}\text { Expenditure share of commodity cost in nest } A M \text { of Armington good } i \\
\text { by sector } g \text { in region } r\end{array}$ \\
\hline$\theta_{c p s}^{A M_{i, g, r}}$ & $\begin{array}{l}\text { Expenditure share of carbon price of carbon pricing scheme cps } \\
\text { in nest } A M \text { of Armington good } i \text { by sector } g \text { in region } r\end{array}$ \\
\hline$\theta_{s}^{M_{i, r}}$ & $\begin{array}{l}\text { Expenditure share of imports from region } s \text { in imports nest } M \\
\text { covering imports of good } i \text { by region } r\end{array}$ \\
\hline$\theta_{Y}^{M T_{i, r, s}}$ & $\begin{array}{l}\text { Expenditure share of commodity cost in gross import costs for good } i \\
\text { imported from region } r \text { to region } s\end{array}$ \\
\hline$\theta_{T}^{M T_{i, r s}}$ & $\begin{array}{l}\text { Expenditure share of transport cost in gross import costs for good } i \\
\text { imported from region } r \text { to region } s\end{array}$ \\
\hline$\theta_{r}^{T}$ & $\begin{array}{l}\text { Expenditure share of transport services from region } r \\
\text { in international provision of transport services }\end{array}$ \\
\hline
\end{tabular}

$$
\begin{aligned}
c_{i, r}^{E N E}:= & {\left[\theta_{\mathrm{ele}}^{E N E_{i, r}}\left(\frac{P A_{\mathrm{ele}, i, r}}{\overline{p a}_{\mathrm{ele}, i, r}}\right)^{1-\sigma^{e n e}}+\theta_{F O S}^{E N E_{i, r}}\left(c_{i, r}^{F O S}\right)^{1-\sigma^{e n e}}\right]^{\frac{1}{1-\sigma^{e n e}}} } \\
c_{i, r}^{F O S}:= & {\left[\theta_{\text {oil }}^{F O S_{i, r}}\left(\frac{P A_{\mathrm{oil} l, i, r}}{\overline{p a}_{\mathrm{oil}, i, r}}\right)^{1-\sigma^{f o s}}+\theta_{\mathrm{col}}^{F O S_{i, r}}\left(\frac{P A_{\mathrm{col}, i, r}}{\overline{p a}_{\mathrm{col}, i, r}}\right)^{1-\sigma^{f o s}}\right.} \\
& \left.+\theta_{\mathrm{gas}}^{F O S_{i, r}}\left(\frac{P A_{\mathrm{gas}, i, r}}{\overline{p a}_{\mathrm{gas}, i, r}}\right)^{1-\sigma^{f o s}}\right]^{\frac{1}{1-\sigma^{f o s}}}
\end{aligned}
$$

Table A.4

Elasticities of substitution.

\begin{tabular}{lll}
\hline Name & Source & Values \\
\hline$\sigma_{\mathrm{MAT}-\mathrm{KLE}}$ & Abrell and Rausch (2016) & $0.2^{\mathrm{b}}$ \\
$\sigma_{\mathrm{KLE}}$ & Abrell and Rausch (2016) & $0.25^{\mathrm{b}}$ \\
$\sigma_{\mathrm{M}}$ & Abrell and Rausch (2016) & $0.3^{\mathrm{b}}$ \\
$\sigma_{\mathrm{KL}}$ & Weighted average of ESUBVA from GTAP 9 & $0.2-1.7$ \\
$\sigma_{\mathrm{ENE}}$ & Abrell and Rausch (2016) & $0.3^{\mathrm{b}}$ \\
$\sigma_{\mathrm{FOS}}$ & Abrell and Rausch (2016) & $0.8^{\mathrm{b}}$ \\
$\sigma_{\mathrm{ff}}$ & Calibrated to price elasticities of supply & $0.003-0.66$ \\
& cru: 0.25, col: 1 gas: 0.5 & \\
$\sigma_{\mathrm{A}}$ & Weighted average of ESUBD from GTAP 9 & $1.9-8.0^{\mathrm{a}}$ \\
$\sigma_{\mathrm{M}}$ & Weighted average of ESUBM from GTAP 9 & $3.8-8.0^{\mathrm{a}}$ \\
\hline
\end{tabular}

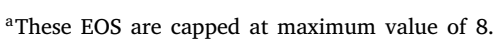

${ }^{b}$ EOS that are multiplied by 1.5 in the 2011 baseline.

For $i \in\{$ col, gas, oil $\}$, the cost functions are

$c_{i, r}^{Y}:=\left[\theta_{E X P}^{Y_{i, r}}\left(c_{i, r}^{E X P}\right)^{1-\sigma^{f f}}+\theta_{E X T}^{Y_{i, r}}\left(c_{i, r}^{E X T}\right)^{1-\sigma^{f f}}\right]^{\frac{1}{1-\sigma^{f f}}}$,

where

$$
\begin{aligned}
c_{i, r}^{E X P} & :=\sum_{j \in I} \theta_{j}^{E X P_{i, r}} \frac{P A_{j, i, r}}{\overline{p a}_{j, i, r}} \\
& +\theta_{\text {lab }}^{E X P_{i, r}} \frac{P F_{\text {lab }, r}}{\overline{p f}_{\text {lab }, r}}+\theta_{\text {cap }}^{E X P_{i, r}} \frac{P F_{\text {cap }, r}}{\overline{p f}_{\text {cap }, r}} \\
c_{i, r}^{E X T} & :=\sum_{j \in I} \theta_{j}^{E X T_{i, r}} \frac{P A_{j, i, r}}{\overline{p a}_{j, i, r}} \\
& +\theta_{\text {lab }}^{E X T_{i, r}} \frac{P F_{\text {lab }, r}}{\overline{p f}_{\text {lab }, r}}+\theta_{\text {cap }}^{E X T_{i, r}} \frac{P F_{\text {cap }, r}}{\overline{p f}_{\text {cap }, r}}+\theta_{\text {res }}^{E X T_{i, r}} \frac{P F S_{\text {res }, i, r}}{\overline{p f s}_{\text {res }, i, r}} .
\end{aligned}
$$

Discrimination between domestic and foreign variants of a commodity class from different countries is represented by a nested Armington aggregation (see Fig. A.4):

$c_{i, g, r}^{A}:=\left[\theta_{A Y}^{A_{i, g, r}}\left(c_{i, g, r}^{A Y}\right)^{1-\sigma^{A}}+\theta_{M}^{A_{i, g, r}}\left(c_{i, g, r}^{A M}\right)^{1-\sigma^{A}}\right]^{\frac{1}{1-\sigma^{A}}}$,

where

$c_{i, g, r}^{A Y}:=\theta_{Y}^{A Y_{i, g, r}} \frac{P Y_{i, r}}{\overline{p y}_{i, r}}+\sum_{c p s} \theta_{c p s}^{A Y_{i, g, r}} \frac{P C O 2_{c p s}}{\overline{p c o 2}_{c p s}}$

$c_{i, g, r}^{A M}:=\theta_{M}^{A M_{i, g, r}}\left(c_{i, r}^{M}\right)+\sum_{c p s} \theta_{c p s}^{A M_{i, g, r}} \frac{P C O 2_{c p s}}{\overline{p c o 2}_{c p s}}$

$c_{i, r}^{M}:=\left[\sum_{s \in R} \theta_{s}^{M_{i, r}}\left(c_{i, r, s}^{M T}\right)^{1-\sigma^{M}}\right]^{\frac{1}{1-\sigma^{M}}}$

$c_{i, r, s}^{M T}:=\theta_{Y}^{M T_{i, r, s}} \frac{P Y_{i, s}}{\overline{p y}_{i, s}}+\theta_{T}^{M T_{i, r, s}} \frac{P T_{\mathrm{trn}}}{\overline{p t}_{\mathrm{trn}}}$

$\forall s \in R$,

where $c p s$ is an index covering all active carbon pricing schemes in the model. ${ }^{29}$ International transport services are priced at $P T_{i}(i \in\{\operatorname{trn}\})$ and are produced with transport services from each region according to a Cobb-Douglas function:

$c_{\mathrm{trn}}^{T}:=\prod_{r \in R}\left(\frac{P Y_{\mathrm{trn}, r}}{\overline{p y}_{\mathrm{trn}, r}}\right)^{\theta_{r}^{T}}$.

$29 \quad \theta_{c p s}^{A Y_{i, r}}$ takes the value zero for all carbon pricing schemes cps that do not apply to the use of input $i$ in sector $g$ of region $r$. There are carbon pricing schemes that cover only single regions (e.g., non-ETS carbon pricing in scenario versions EU ETS + national pricing) and other carbon pricing schemes cover several regions (e.g., carbon pricing in the EU ETS). Some carbon pricing schemes only cover some sectors $g$ (e.g. ETS and non-ETS carbon pricing in scenario versions EU ETS + national pricing and Full ETS). Fossil fuel demand by all sectors $g$ and all regions $r$ are covered by exactly one carbon pricing scheme. 
Table C.1

Ratios of income or expenditure categories according to survey data (EU-SILC or HBS) with categories according to GTAP data.

\begin{tabular}{|c|c|c|c|c|c|c|c|}
\hline \multirow[t]{2}{*}{ Region } & \multirow{2}{*}{$\begin{array}{l}\text { Capital } \\
\text { income }^{\mathrm{a}}\end{array}$} & \multirow{2}{*}{$\begin{array}{l}\text { Labor } \\
\text { income }^{\mathrm{a}}\end{array}$} & \multirow{2}{*}{$\begin{array}{l}\text { Transfer } \\
\text { income }^{\mathrm{b}}\end{array}$} & \multicolumn{2}{|l|}{ Savings $^{c}$} & \multirow{2}{*}{$\begin{array}{l}\text { Consumption of } \\
\text { energy goods }{ }^{\mathrm{a}}\end{array}$} & \multirow{2}{*}{$\begin{array}{l}\text { Consumption of } \\
\text { non-energy goods }\end{array}$} \\
\hline & & & & (EU-SILC) & (Model) & & \\
\hline BEL & 0.21 & 1.20 & 0.07 & 0.31 & 0.47 & 1.18 & 0.67 \\
\hline BGR & 0.17 & 1.13 & 0.60 & 0.70 & 0.81 & 0.56 & 0.50 \\
\hline CYP & 0.34 & 1.28 & 0.33 & 0.51 & 0.29 & 0.70 & 0.75 \\
\hline DEU & 0.23 & 1.18 & 0.12 & 0.95 & 0.77 & 1.13 & 0.57 \\
\hline DNK & 0.21 & 0.99 & 0.37 & 0.42 & 1.41 & 1.09 & 0.84 \\
\hline ESP & 0.33 & 1.04 & 0.82 & 0.51 & 0.95 & 1.38 & 0.75 \\
\hline EST & 0.15 & 1.13 & 0.23 & 0.55 & 0.50 & 0.43 & 0.47 \\
\hline FIN & 0.25 & 0.94 & -2.38 & 0.51 & 1.14 & 0.92 & 0.71 \\
\hline FRA & 0.39 & 1.16 & 0.46 & 0.75 & 0.59 & 1.14 & 0.66 \\
\hline GBR & 0.19 & 1.02 & -0.16 & 1.00 & 0.44 & 1.17 & 0.50 \\
\hline GRC & 0.24 & 1.38 & 0.04 & 0.17 & -0.39 & 0.29 & 0.71 \\
\hline HRV & 0.06 & 1.05 & 0.07 & 0.03 & -0.05 & 0.53 & 0.67 \\
\hline HUN & 0.17 & 0.92 & 0.30 & 0.28 & 0.44 & 0.78 & 0.47 \\
\hline IRL & 0.15 & 0.98 & -0.20 & 1.62 & 5.58 & 1.10 & 0.84 \\
\hline LTU & 0.13 & 0.88 & 0.33 & 0.06 & 0.52 & 0.95 & 0.49 \\
\hline LVA & 0.07 & 1.01 & 0.16 & 0.27 & 0.27 & 0.96 & 0.43 \\
\hline POL & 0.15 & 1.07 & 0.09 & 0.34 & 0.33 & 0.74 & 0.48 \\
\hline PRT & 0.09 & 0.96 & 0.32 & -0.14 & 0.62 & 1.50 & 0.66 \\
\hline ROU & 0.02 & 0.57 & 0.13 & -0.23 & 0.12 & 0.90 & 0.40 \\
\hline SVK & 0.09 & 1.12 & 0.49 & 0.47 & 0.73 & 0.87 & 0.45 \\
\hline SVN & 0.18 & 1.17 & 0.15 & 0.22 & 0.47 & 1.00 & 0.73 \\
\hline
\end{tabular}

Note: "Energy goods" are coal, gas, and refined oil products, and "non-energy goods" are energy intensive goods, transportation, crude oil, electricity, agriculture, other manufactured goods, and services.

${ }^{a}$ For model calibration, GTAP values where split across deciles according to survey data.

${ }^{\mathrm{b}}$ For model calibration, survey data aggregated to deciles were used.

cSince national sums of savings in the model agree with neither survey data nor GTAP, we also give ratio of model values with GTAP values.

For benchmark supply of total fixed endowments by the households in region $r$, we denote labor and capital as $\bar{F}_{f \in\{\text { lab,cap }\}, h, r}$ and natural resources as $\overline{F S}_{\text {res }, i, h, r}$. Using Shephard's lemma, the market clearing equations can be formulated:

$$
\begin{array}{rlrl}
Y_{i, r} & \geq \sum_{s \in R} \frac{\partial c_{i, g, s}^{A}}{\partial P Y_{i, r}} A_{i, g, s}+\frac{\partial c_{i}^{T}}{\partial P Y_{i, r}} T_{i} & \perp & P Y_{i, r} \geq 0 \\
A_{i, g, r} & \geq \sum_{j \in I} \frac{\partial c_{j, r}^{Y}}{\partial P A_{i, g, r}} Y_{j, r}+\frac{\partial c_{r}^{C}}{\partial P A_{i, g, r}} C_{r} & & \\
& +\frac{\partial c_{r}^{G}}{\partial P A_{i, g, r}} G_{r}+\frac{\partial c_{r}^{I}}{\partial P A_{i, g, r}} I_{r} & \perp & P A_{i, g, r} \geq 0 \\
T_{i} & \geq \sum_{(j, g, r) \in I \times G \times R} \frac{\partial c_{j, g, r}^{A}}{\partial P T_{i}} A_{j, g, r} & \perp & P T_{i} \geq 0 \\
\sum_{h} \bar{F}_{\mathrm{cap}, h, r} & \geq \sum_{i \in I} \frac{\partial c_{i, r}^{Y}}{\partial P F_{\mathrm{cap}, r}} Y_{i, r} & \perp & P F_{\mathrm{cap}, r} \geq 0 \\
\sum_{h} \bar{F}_{\mathrm{lab}, h, r} & \geq \sum_{i \in I} \frac{\partial c_{i, r}^{Y}}{\partial P F_{1 \mathrm{ab}, r}} Y_{i, r} & \perp & P F_{\mathrm{lab}, r} \geq 0 \\
\sum_{h} \overline{F S}_{\mathrm{res}, i, h, r} & \geq \frac{\partial c_{i, r}^{Y}}{\partial P F S_{\mathrm{res}, i, r}} Y_{i, r} & \perp & P F S_{\mathrm{res}, i, r} \geq 0 \\
C_{h, r} & \geq \frac{E X P_{h, r}^{C}}{P C_{h, r}} \\
G_{r} & \geq \frac{E X P_{r}^{G}}{P G_{r}} \\
I_{r} & \geq \sum_{h \in H_{r}} \bar{I}_{h, r} \\
\sum_{r \in R} \bar{E}_{c p s, r} \geq \sum_{(i, g, r) \in c p s} \frac{\partial c_{i, g, r}^{A}}{\partial P Y_{i, r}} A_{i, g, r} & \perp \quad P C_{h, r} \geq 0
\end{array}
$$

\begin{tabular}{|c|c|c|}
\hline Region & $\begin{array}{l}\text { Change in economy wide baseline } \\
\text { emissions between } 2030 \text { and } \\
2011(\%)\end{array}$ & $\begin{array}{l}\text { Reduction target for non-ETS } \\
\text { emissions in \% relative to } 2030 \\
\text { baseline }\end{array}$ \\
\hline AUT & -5.6 & -26.6 \\
\hline BEL & -3.7 & -38.6 \\
\hline CYP & -15.9 & -25.0 \\
\hline CZE & -10.6 & -0.5 \\
\hline DNK & -20.9 & -34.5 \\
\hline EST & -2.0 & -34.3 \\
\hline FIN & -16.0 & -29.5 \\
\hline FRA & -11.0 & -26.8 \\
\hline DEU & -1.7 & -33.4 \\
\hline GRC & -20.8 & -9.1 \\
\hline HUN & -7.4 & -3.1 \\
\hline IRL & -1.0 & -35.3 \\
\hline ITA & -16.4 & -14.1 \\
\hline LVA & -7.2 & -16.8 \\
\hline LTU & -13.5 & -8.4 \\
\hline LUX & -13.3 & -39.6 \\
\hline MLT & -5.6 & -23.6 \\
\hline NLD & -7.1 & -36.7 \\
\hline POL & -5.8 & -22.6 \\
\hline PRT & -2.8 & -16.4 \\
\hline SVK & -13.7 & -9.9 \\
\hline SVN & -18.3 & -11.2 \\
\hline ESP & -10.9 & -14.5 \\
\hline SWE & -9.6 & -34.2 \\
\hline GBR & -12.2 & -23.5 \\
\hline CHE & -5.5 & -46.0 \\
\hline NOR & 1.3 & -58.2 \\
\hline BGR & -12.4 & -2.9 \\
\hline HRV & -15.8 & -1.7 \\
\hline ROU & -17.9 & 3.9 \\
\hline EU ETS & -9.6 & -24.9 \\
\hline
\end{tabular}

The consumption budget $E X P_{h, r}^{C}$ is given by factor income net of investment expenditure and a lump-sum transfer from the local government. The consumption budget is further modified by revenue recycling of carbon pricing policies (proportional to variable REVREC $_{r}$ ) and budget balance mechanisms that allow the government to keep real
Table C.2

Projection of baseline $\mathrm{CO}_{2}$ emissions and reduction targets by region.

Note: Norway and Switzerland are included as separate regions in our model and are assumed to be part of the EU ETS by 2030. The reduction target for Norway and Switzerland are 40 and 50 percent in 2030 compared to 1990 levels, respectively.

public spending constant (proportional to PUBCLS ${ }_{p c l s, r}$ ).

${ }_{17} E X P_{h, r}^{C}=\left[\sum_{f \in\{\text { lab }, \mathrm{cap}\}} P F_{f, r} \bar{F}_{f, h, r}\right.$ 


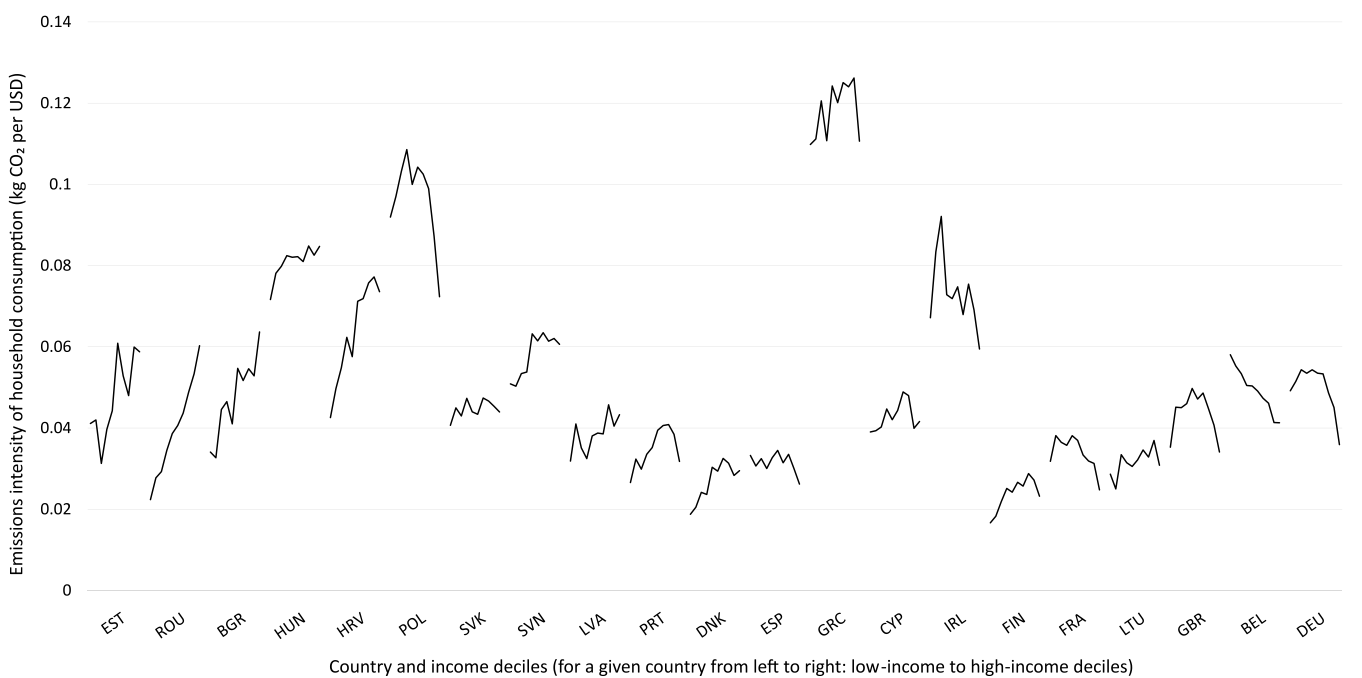

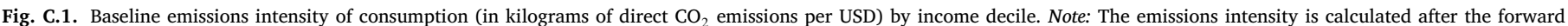
calibration to year 2030 .

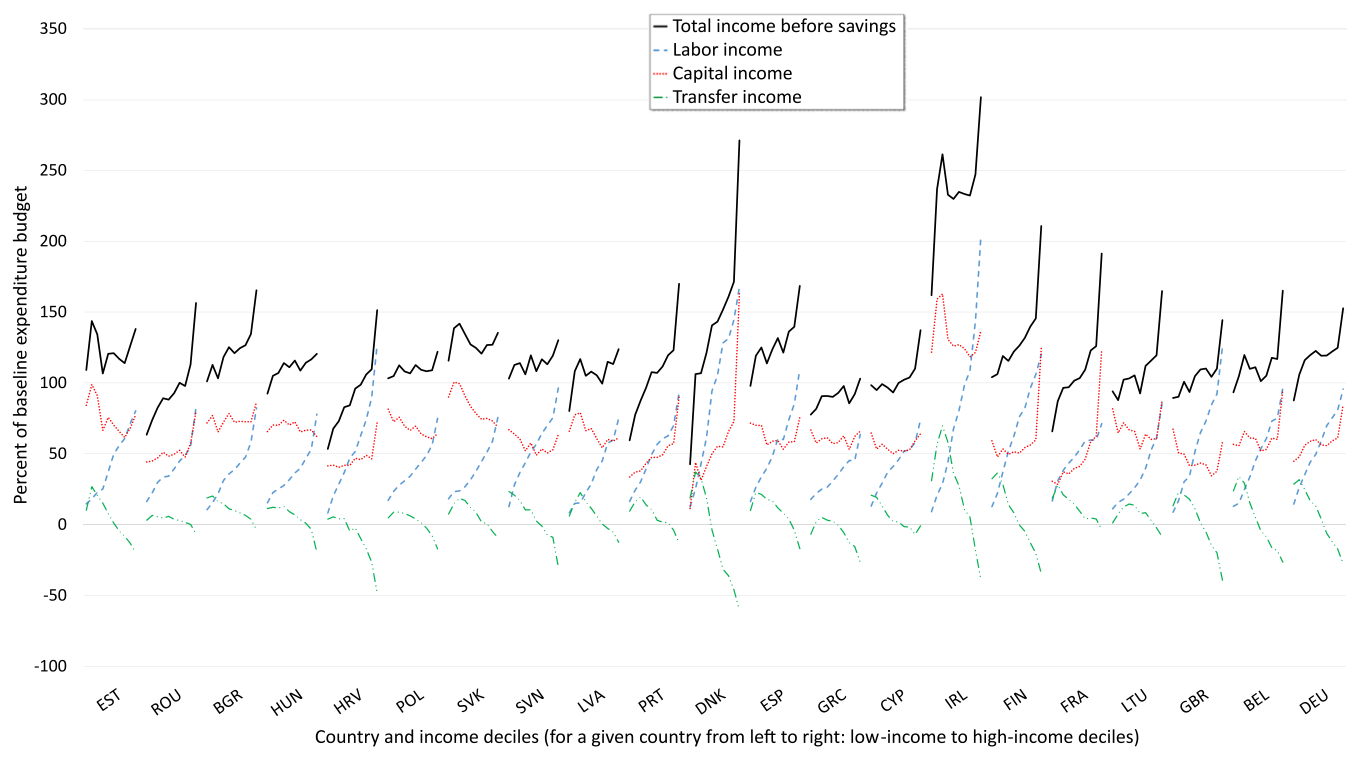

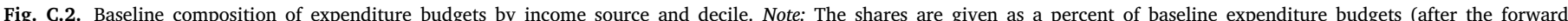

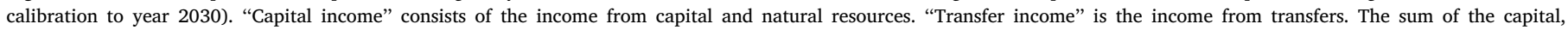
labor, and transfer shares in the figure equals total income (as a percentage of the expenditure budget). Subtracting $100 \%$ from this amount yields the savings share.

$$
\begin{aligned}
& \left.+\sum_{i \in I} P F S_{\mathrm{res}, i, r} \overline{F S}_{\mathrm{res}, i, h, r}-C P I_{r} \overline{h t a x}_{h, r}\right] \\
& \cdot\left(1-\mathrm{PUBCLS}_{\mathrm{inc}, \mathrm{r}}\right) \\
& -P I N V_{r} \cdot \bar{I}_{h, r}+C P I_{r} \cdot \frac{\text { REVREC }_{r}}{\sum_{h h \in H_{r}} 1} \\
& -C P I_{r} \cdot \bar{C}_{h, r} \cdot \mathrm{PUBCLS}_{\mathrm{bmk}, \mathrm{r}}
\end{aligned}
$$$$
\begin{aligned}
& -C P I_{r} \cdot \frac{\sum_{h h \in H_{r}} \overline{h t a x}_{h h, r}}{\left|\sum_{h h \in H_{r}} \overline{h t a x}_{h h, r}\right|} \overline{h t a x}_{h, r} \cdot \text { PUBCLS }_{\mathrm{trf}, \mathrm{r}} \\
& -C P I_{r} \cdot \frac{\mathrm{PUBCLS}_{\mathrm{co} 2 \mathrm{r}, \mathrm{r}}}{\sum_{h h \in H_{r}} 1}
\end{aligned}
$$ 

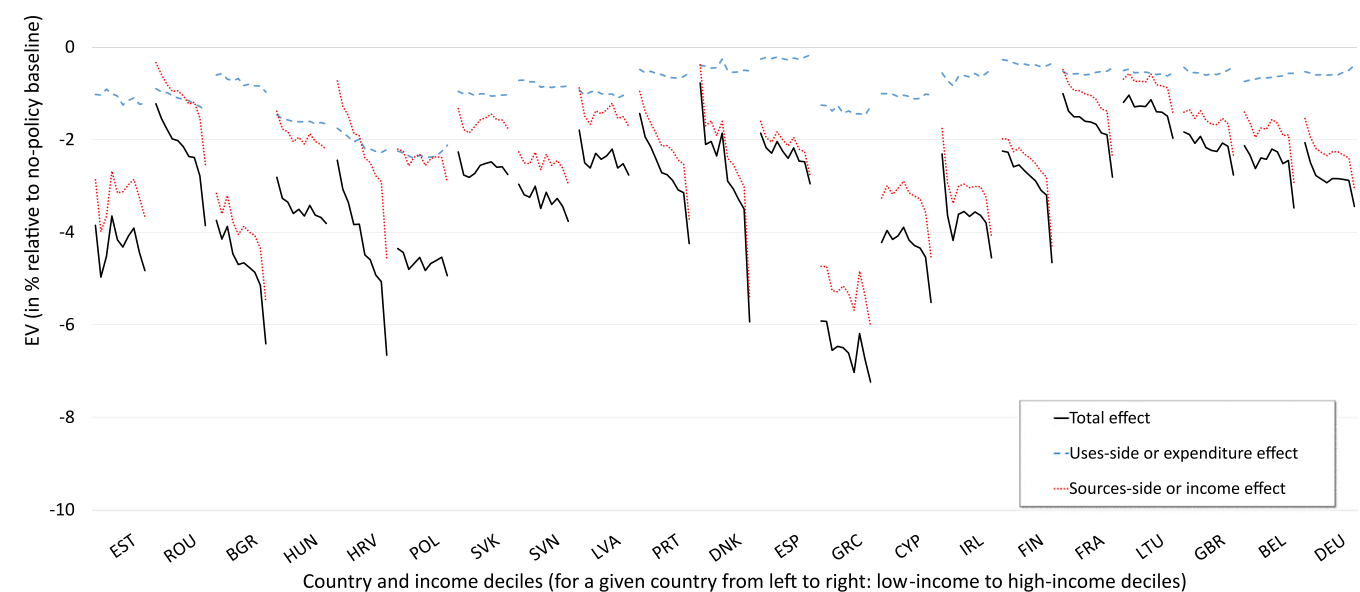

Panel (a): Full ETS

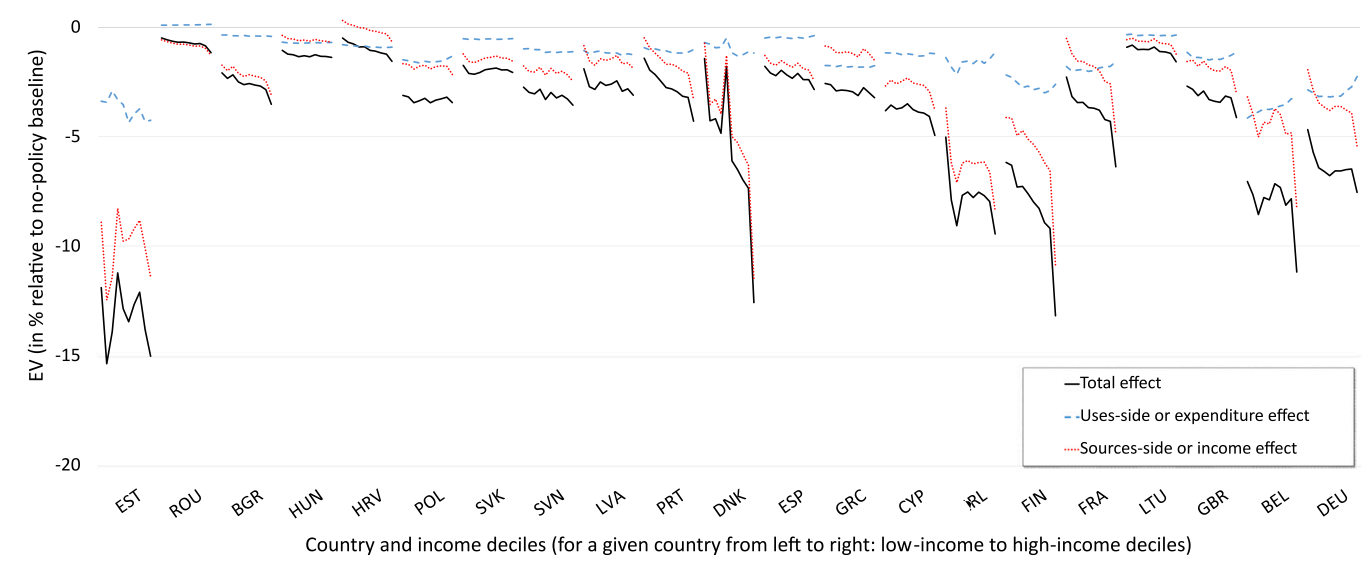

Panel (b): EU ETS + national pricing

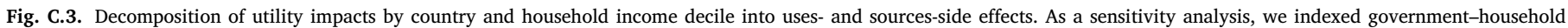
transfers by wages rather than by the national consumer price indices as in Fig. 6 .

where

$C P I_{r}:=\frac{\sum_{(i, h) \in I \times H_{r}} P A_{i, \mathrm{C}, r} \frac{\partial c_{h, r}^{C}}{\partial P A_{i, C, r}} C_{h, r}}{\sum_{h \in H_{r}} \bar{C}_{h, r}}$,

is a consumption price index by model region.

The expenditure budget for public spending by the government, on the other hand, is given by revenues from taxation and transfers to (or from) the households.

$$
\begin{aligned}
E X P_{r}^{G}= & \sum_{i \in I} t o_{i, r} \cdot P Y_{i, r} \cdot Y_{i, r} \\
& +\sum_{i \in I} Y_{i, r} \cdot\left[t f_{\text {lab }, i, r} P F_{1 \mathrm{ab}, r} \frac{\partial c_{i, r}^{Y}}{\partial P F_{\mathrm{lab}, r}}+t f_{\mathrm{cap}, i, r} P F_{\mathrm{cap}, r} \frac{\partial c_{i, r}^{Y}}{\partial P F_{\mathrm{cap}, r}}\right. \\
& \left.\quad+t f_{\mathrm{res}, i, r} P F S_{\mathrm{res}, i, r} \frac{\partial c_{i, r}^{Y}}{\partial P F S_{\mathrm{res}, i, r}}\right] \\
& +\sum_{(g, i) \in G \times I} t i_{i, g, r} \cdot P A_{i, g, r} \cdot A_{i, g, r}+\sum_{i \in I} \mathrm{PUBCLS}_{\mathrm{vat}, r} \cdot P A_{i, c, r} \cdot A_{i, c, r}
\end{aligned}
$$

$$
\begin{aligned}
& +\sum_{(i, s) \in I \times R \backslash\{r\}}\left[t e_{i, r, s} P Y_{i, r} \frac{\partial c_{i, g, s}^{A}}{\partial P Y_{i, r}} A_{i, s}\right. \\
& \left.+t m_{i, s, r}\left(1+t e_{i, s, r}\right) P Y_{i, s} \frac{\partial c_{i, g, r}^{A}}{\partial P Y_{i, s}} A_{i, r}\right] \\
& +C P I_{r} \cdot \sum_{h \in H_{r}} \overline{h t a x}_{h, r} \\
& +\sum_{h \in H_{r}}\left[\sum_{f \in\{1 \mathrm{ab}, \mathrm{cap}\}} P F_{f, r} \bar{F}_{f, h, r}+\sum_{i \in I} P F S_{\mathrm{res}, i, r} \overline{F S}_{\mathrm{res}, i, h, r}\right. \\
& -C P I_{r} \cdot \overline{R E V R E C}_{r}+C P I_{r} \cdot \sum_{h \in H_{r}} \bar{C}_{h, r} \cdot \mathrm{PUBCLS}_{\mathrm{bmk}, \mathrm{r}} \\
& +C P I_{r} \cdot\left|\sum_{h h \in H_{r}} \overline{h t a x}_{h h, r}\right| \cdot \mathrm{PUBCLS}_{\mathrm{trf}, \mathrm{r}} \\
& +C P I_{r} \cdot \mathrm{PUBCLS}_{\mathrm{co} 2, \mathrm{r}}+C P I_{\mathrm{USA}} \cdot \overline{v b}_{r}+\sum_{c p s} P C O 2_{c p s} \cdot \bar{E}_{c p s, r} .
\end{aligned}
$$


The variables PUBCLS ${ }_{p c l, r}$ and REVREC $_{r}$ are determined by the two conditions

$$
\begin{aligned}
& E X P_{r}^{G}={\overline{E X P^{G}}}_{r} \\
& C P I_{r} \cdot \operatorname{REVREC}_{r} \geq \sum_{c p s} P C O 2_{c p s} \cdot \bar{E}_{c p s, r} \quad \perp \quad \operatorname{REVREC}_{r} \geq 0,
\end{aligned}
$$

where PUBCLS ${ }_{p c l, r}$ is unbounded (free) for one $p c l \in\{$ vat, co2, bmk, inc, $\operatorname{trf}\}$ and fixed to zero for the other. For this paper, $p c l=$ vat has been implemented: Consumption expenditure is uniformly taxed to target government expenditure budgets.

\section{Appendix B. Data harmonization}

National aggregates of survey data do not agree with national accounts in GTAP. For a consistent linking of the CGE model to the microsimulation of household demand the two data sources need to be harmonized. For this we match survey results with consumption goods and income categories in GTAP and scale the survey results so that they match national accounts. The following description of the harmonization procedure employed in this study omits the region index $r$.

Aggregating survey observations into income deciles, we get labor income $L_{h}$, capital income $K_{h}$, transfers $T_{h}$, and expenditures $E_{i, h}$ for the CGE model's commodities $i$ by income decile $h$. We identify the residual between income and expenditure as savings $S_{h}=L_{h}+K_{h}+T_{h}-$ $\sum_{i} E_{i, h}$. At the same time we observe numbers for the same categories in the national accounts: labor income $\bar{L}$, capital income $\bar{K}$, resource income $\bar{R}$, investments $\bar{S}$, and expenditures $\bar{E}_{i}$. We infer the transfers between households and the state as $\bar{T}=\bar{E}_{i}+\bar{S}-\bar{L}-\bar{K}-\bar{R}$.

In order to arrive at income and expenditure of calibrated deciles for the model, we establish labor income $\tilde{L}_{h}$, capital income $\tilde{K}_{h}$, resource income $\tilde{R}_{h}$, transfers $\tilde{T}_{h}$, savings $\tilde{S}_{h}$, and expenditures $\tilde{E}_{i, h}$ according to

$$
\begin{aligned}
\tilde{L}_{h} & =\bar{L} \frac{L_{h}}{\sum_{h^{\prime}} L_{h^{\prime}}} \\
\tilde{K}_{h} & =\bar{K} \frac{K_{h}}{\sum_{h^{\prime}} K_{h^{\prime}}} \\
\tilde{R}_{h} & =\bar{R} \frac{K_{h}}{\sum_{h^{\prime}} K_{h^{\prime}}} \\
\tilde{T}_{h} & =T_{h} \\
\tilde{E}_{\mathrm{oi1}, h} & =\bar{E}_{\mathrm{oi1}, h} \frac{E_{\mathrm{oil} 1, h}}{\sum_{h^{\prime}} E_{\mathrm{oil}, h^{\prime}}} \\
\tilde{E}_{\mathrm{col}, h} & =\bar{E}_{\mathrm{col}, h} \frac{E_{\mathrm{col}, h}}{\sum_{h^{\prime}} E_{\mathrm{col}, h^{\prime}}} \\
\tilde{E}_{\mathrm{gas}, h} & =\bar{E}_{\mathrm{gas}, h} \frac{E_{\mathrm{gas}, h}}{\sum_{h^{\prime}} E_{\mathrm{gas}, h^{\prime}}} \\
\tilde{E}_{n e, h} & =\bar{E}_{n e, h} \frac{\sum_{n e^{\prime}} E_{n e^{\prime}, h}}{\sum_{n e^{\prime}, h^{\prime}} E_{n e^{\prime}, h^{\prime}}} \\
\tilde{S}_{h} & =\tilde{L}_{h}+\tilde{K}_{h}+\tilde{R}_{h}+\tilde{T}_{h}-\sum_{i} \tilde{E}_{i, h},
\end{aligned}
$$

where index ne covers all consumption goods except oil, col, and gas.

\section{Appendix C. Additional figures and tables}

See Figs. C.1-C.3 and Tables C.1 and C.2.

\section{References}

Abrell, J., Rausch, S., 2016. Cross-country electricity trade renewable energy and European transmission infrastructure policy. J. Environ. Econ. Manag. 79, 87-113. http://dx.doi.org/10.1016/j.jeem.2016.04.001.
Achtnicht, M., von Graevenitz, K., Koesler, S., Löschel, A., Schoeman, B., Tovar Reaños, M.A., 2019. Road transport and its potential inclusion in the EU ETS. In: Gawel, E., Strunz, S., Lehmann, P., Purkus, A. (Eds.), The European Dimension of Germany's Energy Transition: Opportunities and Conflicts. Springer International Publishing, Cham, pp. 493-508. http://dx.doi.org/10.1007/978-3-030-03374-3_28.

Aguiar, A., Narayanan, B., McDougall, R., 2016. An overview of the GTAP 9 data base. J. Glob. Econ. Anal. 1 (1), 181-208. http://dx.doi.org/10.21642/JGEA.010103AF.

Ancev, T., 2011. Policy considerations for mandating agriculture in a greenhouse gas emissions trading scheme. Appl. Econ. Perspect. Policy 33 (1), 99-115. http: //dx.doi.org/10.1093/aepp/ppq031.

Armington, P.S., 1969. A theory of demand for products distinguished by place of production. Staff Pap. Int. Monet. Fund 16 (1), 159-178, https://www.jstor.org/ stable/3866403.

Atkinson, A.B., 1970. On the measurement of inequality. J. Econom. Theory 2 (3), 244-263. http://dx.doi.org/10.1016/0022-0531(70)90039-6.

Böhringer, C., Hoffmann, T., Lange, A., Löschel, A., Moslener, U., 2005. Assessing emission regulation in Europe: An interactive simulation approach. Energy J. 26 (4), 1-21, http://www.jstor.org/stable/41323070.

Böhringer, C., Hoffmann, T., Manrique-de Lara-Peñate, C., 2006. The efficiency costs of separating carbon markets under the EU emissions trading scheme: A quantitative assessment for Germany. Energy Econ. 28 (1), 44-61. http://dx.doi.org/10.1016/ j.eneco.2005.09.001.

De Cara, S., Vermont, B., 2011. Policy considerations for mandating agriculture in a greenhouse gas emissions trading scheme: A comment. Appl. Econ. Perspect. Policy 33 (4), 661-667. http://dx.doi.org/10.1093/aepp/ppr027.

2021. Directive 2009/29/EC of the European Parliament and of the Council of 23 April 2009 amending Directive 2003/87/EC so as to improve and extend the greenhouse gas emission allowance trading scheme of the community. Off. J. Eur. Union. L 140/63, https://eur-lex.europa.eu/legal-content/EN/TXT/?uri=celex:32009L0029.

2021. Directive EU 2018/410 of the European Parliament and of the Council of 14 March 2018 amending Directive 2003/87/EC to enhance cost-effective emission reductions and low-carbon investments, and decision EU 2015/1814. Off. J. Eur. Union L 76/3, https://eur-lex.europa.eu/legal-content/EN/TXT/?uri=CELEX: 32018 L0410.

European Commission, 2021. Proposal for a Directive of the European Parliament and of the Council amending Directive 2003/87/EC establishing a system for greenhouse gas emission allowance trading within the Union, Decision (EU) 2015/1814 concerning the establishment and operation of a market stability reserve for the Union greenhouse gas emission trading scheme and Regulation (EU) 2015/757. https://ec.europa.eu/info/law/better-regulation/have-your-say/initiatives/12660Climate-change-updating-the-EU-emissions-trading-system-ETS-_en.

Flachsland, C., Brunner, S., Edenhofer, O., Creutzig, F., 2011. Climate policies for road transport revisited (II): Closing the policy gap with cap-and-trade. Energy Policy 39 (4), 2100-2110. http://dx.doi.org/10.1016/j.enpol.2011.01.053.

Goulder, L.H., Hafstead, M.A., Kim, G., Long, X., 2019. Impacts of a carbon tax across US household income groups: What are the equity-efficiency trade-offs? J. Public Econ. 175, 44-64. http://dx.doi.org/10.1016/j.jpubeco.2019.04.002.

Goulder, L.H., Parry, I.W.H., 2008. Instrument choice in environmental policy. Rev. Environ. Econ. Policy 2 (2), 152-174. http://dx.doi.org/10.1093/reep/ren005.

Heinrichs, H., Jochem, P., Fichtner, W., 2014. Including road transport in the EU ETS (European Emissions Trading System): A model-based analysis of the German electricity and transport sector. Energy 69, 708-720. http://dx.doi.org/10.1016/j. energy.2014.03.061.

Labandeira, X., Linares, P., Rodríguez, M., 2009. An integrated approach to simulate the impacts of carbon emissions trading schemes. Energy J. 30, 217-237, http: //www.jstor.org/stable/41323217.

Landis, F., Heindl, P., 2019. Renewable energy targets in the context of the EU ETS: Whom do they benefit exactly? Energy J. 40 (6), https://ideas.repec.org/a/aen/ journl/ej40-6-landis.html.

Lanz, B., Rutherford, T.F., 2016. GTAPinGAMS: Multiregional and small open economy models. J. Glob. Econ. Anal. 1 (2), 1-77, http://dx.doi.org/10.21642/JGEA. 010201AF.

Layard, R., Mayraz, G., Nickell, S., 2008. The marginal utility of income. J. Public Econ. 92 (8), 1846-1857. http://dx.doi.org/10.1016/j.jpubeco.2008.01.007.

Mathiesen, L., 1985. Computation of economic equilibria by a sequence of linear complementarity problems. In: Manne, A.S. (Ed.), Economic Equilibrium: Model Formulation and Solution. In: Mathematical Programming Studies, Springer, Berlin, Heidelberg, pp. 144-162. http://dx.doi.org/10.1007/BFb0121030.

Metcalf, G.E., 2009. Market-based policy options to control U.S. greenhouse gas emissions. J. Econ. Perspect. 23, 5-27. http://dx.doi.org/10.1257/jep.23.2.5.

Rausch, S., Karplus, V.J., 2014. Market vs. regulation: The efficiency and distributional impacts of U.S. climate policy proposals. Energy J. 35, 199-228. http://dx.doi.org/ 10.5547/01956574.35.SI1.11.

Rausch, S., Metcalf, G., Reilly, J., 2011. Distributional impacts of carbon pricing: A general equilibrium approach with micro-data for households. Energy Econ. 33, S20-S33. http://dx.doi.org/10.1016/j.eneco.2011.07.023.

Rausch, S., Schwarz, G., 2016. Household heterogeneity, aggregation, and distributional impacts of environmental taxes. J. Public Econ. 38 (43-57), http://dx.doi.org/10. 1016/j.jpubeco.2016.04.004. 
van Ruijven, B.J., O'Neill, B.C., Chateau, J., 2015. Methods for including income distribution in global CGE models for long-term climate change research. Energy Econ. 51, 530-543. http://dx.doi.org/10.1016/j.eneco.2015.08.017.

Rutherford, T.F., 1995. Extension of GAMS for complementarity problems arising in applied economic analysis. J. Econom. Dynam. Control 19 (8), 1299-1324. http://dx.doi.org/10.1016/0165-1889(94)00831-2.

Rutherford, T.F., 1999. Applied general equilibrium modeling with MPSGE as a GAMS subsystem: An overview of the modeling framework and syntax. Comput. Econ. 14 (1), 1-46. http://dx.doi.org/10.1023/A:1008655831209.
Treaty of Accession of Croatia, 2012. Off. J. Eur. Union. L 112, https://eur-lex.europa eu/legal-content/EN/TXT/?uri=celex:12012J/TXT.

Williams III, R.C., Gordon, H., Burtraw, D., Carbone, J.C., Morgenstern, R.D., 2015 The initial incidence of a carbon tax across income groups. Natl. Tax J. 68 (1), 195-214, https://ideas.repec.org/a/ntj/journl/v68y2015i1p195-214.html.

World Bank, 2020. Purchasing Power Parities and the Size of World Economies: Results from the 2017 International Comparison Program. World Bank, Washington, DC, http://dx.doi.org/10.1596/978-1-4648-1530-0, License: Creative Commons Attribution CC BY 3.0 IGO. 